\title{
On-Site Inspection Procedures for SNM Doorway Monitors
}

\section{MASTER}

$\frac{\sigma}{\frac{\sigma}{6}}$

$\frac{4}{0}$

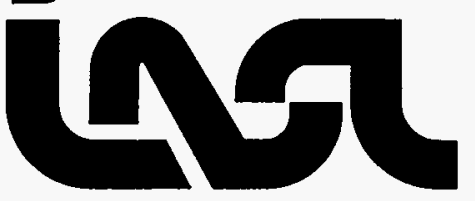


An Affirmative Action/Equal Opportunity Employer

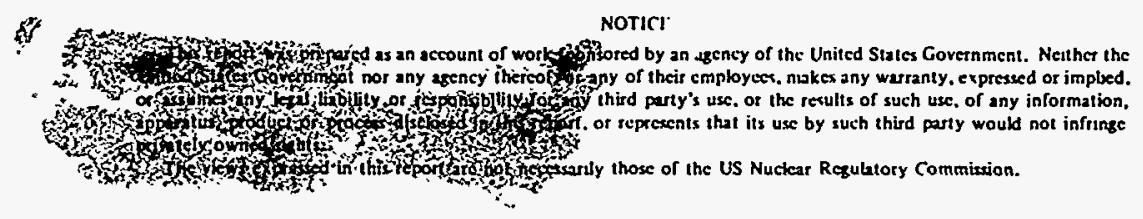




\section{DISCLAIMER}

Portions of this document may be illegible in electronic image products. Images are produced from the best available original document. 


\section{On-Site Inspection Procedures for SNM Doorway Monitors}

Paul E. Fehlau

Thomas E. Sampson

Carl N. Henry

John M. Bieri

William H. Chambers

Manuscript submitted: January 1979

Date published: August 1979

Prepared for

Office of inspection and Enforcement US Nuclear Regulatory Commission Washington, DC 20555

NRC FIN No. 1209
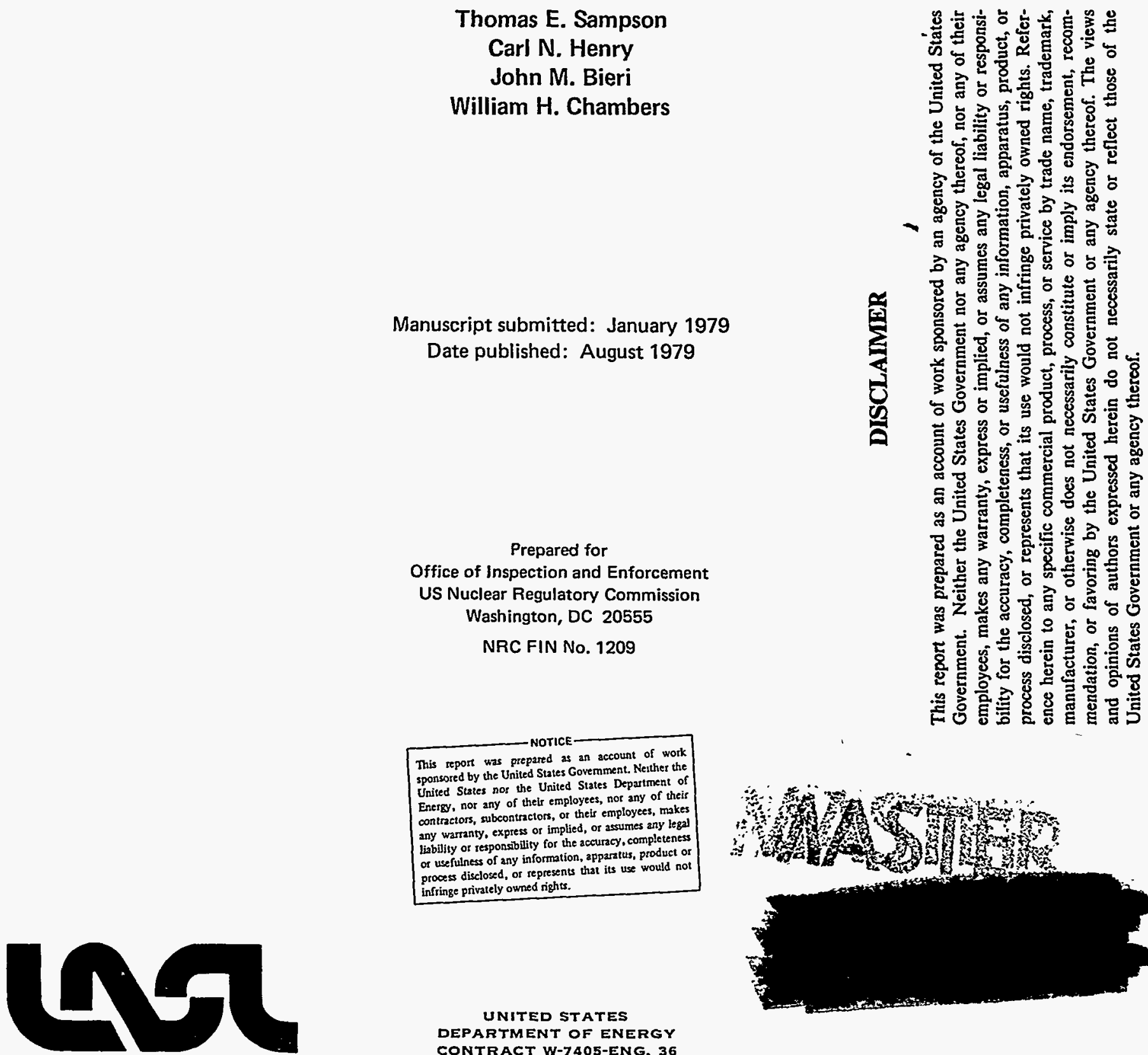

UNITED STATES DEPARTMENT OF ENERGY CONTRACT W-7405-ENG. 36

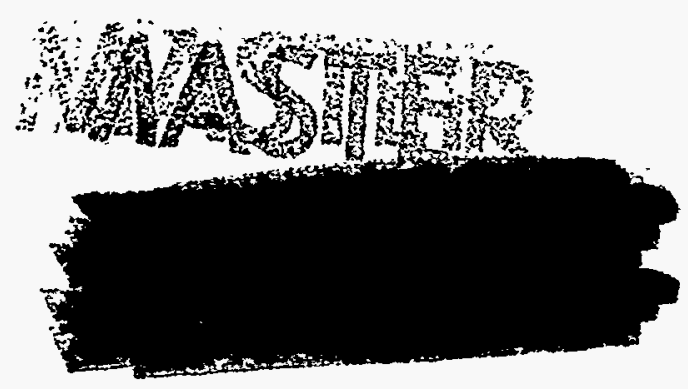


CONTENTS

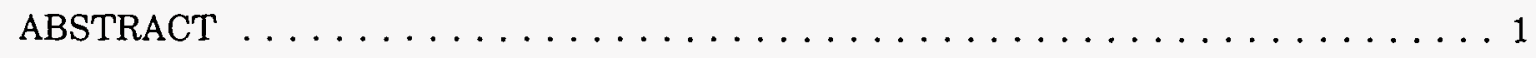

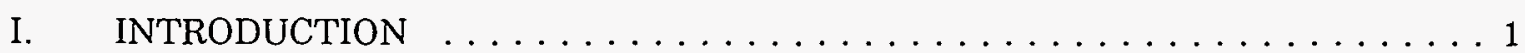

II. PERFORMANCE SPECIFICATIONS FOR SNM

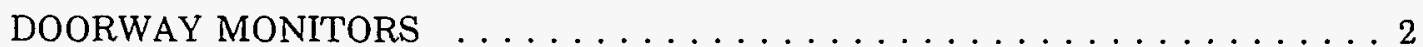

DRAFT REVISED REGULATORY GUIDE $5.27 \ldots \ldots \ldots \ldots \ldots$

III. TECHNICAL DATA FOR COMMERCIAL SNM.MONITORS $\ldots \ldots \ldots \ldots \ldots$

IV. BASIC INSPECTION TECHNIQUES FOR SNM DOORWAY MONITORS $\ldots . .30$

V. DRAFT SNM DOORWAY MONITOR INSPECTION PROCEDURES $\ldots \ldots \ldots 34$

VI. TRIAL DOORWAY MONITOR INSPECTION $\ldots \ldots \ldots \ldots \ldots \ldots \ldots \ldots$

VII. CONTINUING SUPPORT AND DISCUSSION $\ldots \ldots \ldots \ldots \ldots \ldots \ldots$

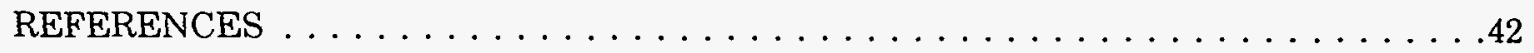

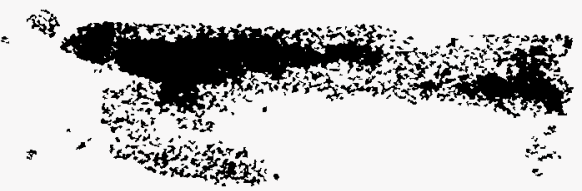




\title{
ON-SITE INSPECTION PROCEDURES FOR SNM DOORWAY MONITORS
}

\author{
by \\ Paul E. Fehlau, Thomas E. Sampson, Carl N. Henry, \\ John M. Bieri, and William H. Chambers
}

\begin{abstract}
This report discusses a program to develop inspection techniques for performance of special nuclear material (SNM) doorway monitors installed at Nuclear Regulatory Commission licensed facilities. The program included a review of performance requirements, a compilation of data on commercially available SNM monitors, the proposal of an inspection scheme, and trial inspections.
\end{abstract}

\section{INTRODUCTION}

The work reported here was undertaken as a Nuclear Regulatory Commission (NRC) Office of Inspection and Enforcement task to develop and test inspection procedures for special nuclear material (SNM)* doorway monitors at NRC-licensed facilities. We wanted a method to determine whether SNM doorway monitors used in a plant environment were meeting the requirements of NRC Regulatory Guide 5.27.

Our investigation was divided into separate stages, the first of which began with a critical look at Regulatory Guide 5.27 and led to a proposed revision of that document. The second stage was the compilation of information on SNM monitoring equipment that was commercially available then. The third stage involved investigating the basic techniques for inspection. From the results, a detailed inspection procedure for use by a security-trained inspector was developed. The fourth stage required a trial of the proposed inspection procedure, and the fifth stage asked for guidance on continued support needed to back up the inspection effort.

Each stage of the investigation was followed by a report to NRC, giving details and results of that part of the work. Here we intend to summarize the content of those reports and to give detail where it would guide Department of Energy (DOE) personnel who work with SNM monitoring equipment. Our intent is also to detail the inspection procedure enough to assist the operations offices of DOE (formerly the Energy Research and Development Administration) who are responsible for proper SNM monitor use at the DOE facilities.

*Plutonium and enriched uranium. 


\section{PERFORMANCE SPECIFICATIONS FOR SNM DOORWAY MONITORS}

Before we could develop Regulatory Guide 5.27 compliance inspection procedures for SNM doorway monitors, we first had to revise the Regulatory Guide. Some major deficiencies in the original document were that the SNM source materials used to specify sensitivity requirements were not well characterized, the information given to specify and regulate false-alarm rate was not correct, and the specifications for testing performance were incomplete. We wrote a revision of Regulatory Guide 5.27, making it precise and usable, and used it in the rest of the work. As yet, it is just a draft and is open to change before adoption by NRC. The content of the draft was greatly influenced by our DOE-supported work ${ }^{1,2}$ in SNM doorway monitor specification and evaluation, and the document is consistent with the DOE doorway monitor standard.

Our proposed revision of Regulatory Guide 5.27 is given on pp. 3-10. The bordered paper is used to set it off as a stand-alone document within this report. We include it as part of the text because we need to give the performance requirements included in it before we discuss inspection procedures. 


\title{
DRAFT REVISED NRC REGULATORY GUIDE 5.27
}

\author{
Special Nuclear Material Doorway Monitors
}

\section{A. Introduction}

Paragraph (b), "Exit Requirement," of paragraph 73.60, "Additional Requirements for the Physical Protection of Special Nuclear Material at Fixed Sites," of 10 CFR (Code of Federal Regulations) Part 73, "Physical Protection of Plants and Materials," requires that individuals exiting from material access areas be searched for concealed special nuclear materials (SNM). This guide describes means acceptable to the Regulatory staff for using SNM doorway monitors to comply with that requirement.

\section{B. Discussion}

SNM doorway monitors provide an efficient, sensitive, and reasonably unobtrusive means of searching individuals exiting from a material access area for concealed SNM. With proper installation and operation, gram or less quantities of SNM can be detected reliably while a low falsealarm rate is maintained.

\section{Theory of Operation}

The doorway monitor comprises a detector unit(s), associated electronics, and alarm logic. The detector unit(s) is sensitive to the radiations that emanate from the SNM and responds to these radiations (usually gamma rays) by generating current pulses. These pulses are amplified, filtered, and fed to alarm logic, which interprets the number (or rate) of pulses in some period of time, for example, $1 \mathrm{~s}$. The alarm logic may be either a digital or an analog system; in either, if the number (or rate) of pulses exceeds an alarm level, an alarm occurs.

\section{General Characteristics}

Typically, the detectors of a doorway monitor are sodium iodide scintillators or solid or liquid organic scintillators. Geiger-Müller detectors have also been used in this application, although their lower intrinsic efficiency makes them less suitable than scintillation detectors.

Detectors are arranged so that a detection area is defined by a plane perpendicular to the line of passage of individuals through the doorway monitor. Various arrangements of the detectors are possible; however, specific placement of detectors is usually dictated by the need to eliminate dead spots.

Some commercially available doorway monitors are equipped with an automatic background updating system. The automatic background updating system periodically monitors and averages the background. A doorway monitor equipped with an automatic background updating system also may be provided with a system to indicate that the sensitive area is occupied. When the sensitive area is occupied, the radiation level detected by the doorway monitor is compared with an alarm level derived from the mean background. If the radiation level is "significantly" 
greater than the background level, an alarm occurs. Significance is usually determined by comparing the radiation level when the sensitive area is occupied with the mean background plus some multiple of the square root of the mean background, * although other schemes are possible.

Thus, the condition for an alarm can be written as

$$
\mathrm{G}>\mathrm{B}+\mathrm{n} \sqrt{\mathrm{B}}
$$

where $B$ is the mean background, $G$ is the radiation level with the sensitive area occupied, and $n$ is a multipler, usually an integer. The value of $n$ directly affects the false-alarm rate, and the combination of $B$ and $n$ affects the sensitivity.

Even though a doorway monitor with an automatic background updating system can be left unattended, physical security requires other doorway surveillance measures. Techniques to accomplish this are described in Sec. C.2.b of this Guide.

Doorway monitors not equipped with an automatic background updating system should be able to determine the mean background with manual control, when required, and to derive the alarm level from the mean background by adding either $n \sqrt{B}$, a percentage of $B$, or a fixed increment to the mean background. The inequality above still applies with $n \sqrt{B}$ replaced by a percentage of $\mathrm{B}$ or a fixed increment.

Whether or not a doorway monitor is equipped with an automatic background updating system, high background activity will result in decreased sensitivity or increased false-alarm rate, depending on the alarm algorithm. Measuring signals for longer periods will somewhat compensate for high background; however, longer measurement periods will make doorway monitor use less convenient

\section{Regulatory Position}

\section{Minimum Qualification for SNM Doorway Monitors}

\section{a. General}

(1) SNM doorway monitors should be used in conjunction with a metal detector and should be installed in a passageway (see Regulatory Guide 5.7, "Control of Personnel Access to Protected Areas, Vital Areas, and Material Access Areas") so that objects passed around or through the detection area are under surveillance.

(2) The detector elements should be designed and positioned so that detection sensitivity is as uniform as possible over the detection area.

(3) Power, sensitivity, and other controls of the doorway monitor should be tamper-safe when unattended and should be protected against unauthorized or accidental changing of control settings when attended.

(4) Signal lines connecting alarm relays to a remote-alarm monitor should be supervised.

(5) Some doorway monitors may require that an individual occupy the detection area for a specified time, one longer than a normal walking pace would provide. Such a monitor should be provided with a device to assure that the detection area is occupied for the requisite time. An aural and visual indication should be given if an individual being searched does not occupy the area for the required time.

\footnotetext{
*The square root of the mean of a Poisson-distribured quantity (such as the background) is the unbiased estimate of the
} standard deviation of the quantity. 


\section{b. Sensitivity Specifications}

The specifications given here are for performance in a $20-\mu \mathrm{R} / \mathrm{h}$ or greater background, which is near the maximurn natural background rate in the continental United States. The performance of the monitcr would be expected to improve with decreasing background; so where a choice of operating location is available, the lowest background environment is preferred.

The test sources are specified as spheres to maximize self-absorption of the gamma radiation and provide the minimum signal. Test sources having the same mass but other shapes can be expected to give higher gamma output and would be more easily detected by a monitor. Similarly, the enrichment and composition of sources are specified to control the gamma signal.

The specified performance is given as a $50 \%$ detection probability for convenience in measurement. Figure 1 gives the number of passages required to determine a detection probability of $50 \%$ with $95 \%$ confidence as a function of passages detected. Note the rapid increase in the required number of passages as the percentage of passages detected decreases toward $50 \%$. Practical

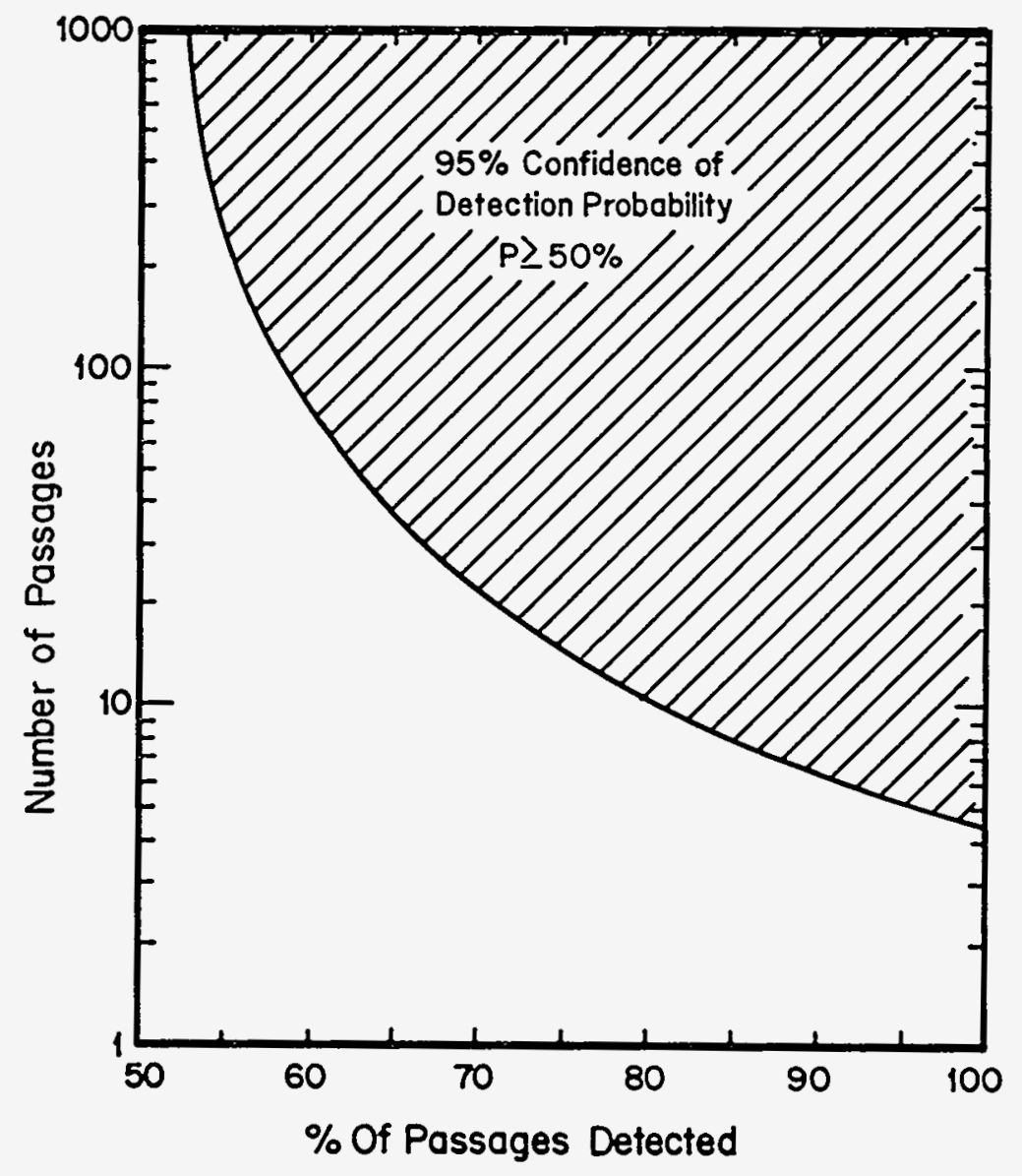

Fig. 1.

Number of detected passages needed to determine a 50\% detection probability with $95 \%$ confidence. 
testing procedure may be limited to as few as 20 passages, particularly where tests must be carried out weekly. Thus, although the minimum performance requirements are stated at $50 \%$ detection probability, the practical requirement is much higher. That is, unless the monitor actually is capable of detecting at least $75 \%$ of the passages unfailingly, then sometime, it will not pass a 20 -passage testing procedure.

At the specified sensitivity, the statistical false-alarm rate of the monitor shall be such that, on the average, 1 or fewer false alarms occur during 1000 passages.

\section{c. Source Specifications}

(1) Plutonium-239. A doorway monitor used to detect plutonium should be capable of detecting with $50 \%$ or greater probability a minimum of $0.5 \mathrm{~g}$ of ${ }^{289} \mathrm{Pu}$ in spherical form. The ${ }^{230} \mathrm{Pu}$ source shall be not more than $0.5 \mathrm{~g}$ of ${ }^{289} \mathrm{Pu}$ in plutonium metal containing at least $99.50 \mathrm{wt} \%$ plutonium and having a minimum density of $19.44 \mathrm{~g} / \mathrm{cm}^{8}$. The ${ }^{239} \mathrm{Pu}$ content shall be at least $93.5 \%$ and the ${ }^{240} \mathrm{Pu}$ content shall be less than $6.5 \%$. The source shall contain less than $1000 \mathrm{ppm}$ ${ }^{241} \mathrm{Am}$.

The source must be encapsulated for contamination protection in at least $0.5 \mathrm{~mm}$ of stainless steel, nickel, or equivalent. Usually double encapsulation will be required and is practical within the specified minimum thickness.

(2) Uranium-233. Adequate sensitivity for ${ }^{283} \mathrm{U}$ may be demonstrated by meeting the requirements of (1) above.

(3) Uranium-235. A doorway monitor used for ${ }^{285} \mathrm{U}$ should detect with $50 \%$ or greater probability the passage of a spherical source of highly enriched uranium metal. The source shall be not more than $10 \mathrm{~g}$ of ${ }^{286} \mathrm{U}$ in uranium metal of at least $93 \%$ enrichment containing at least $99.75 \mathrm{wt} \%$ uranium. Encapsulation of the test source shall be in at least $0.05 \mathrm{~mm}$ of plastic or equivalent.

(4) Special Test Sources. Adequate sensitivity for either plutonium or uranium also may be demonstrated by using equivalent sources specifically approved by the Regulatory staff for this purpose as discussed in Appendix A [of this draft].

\section{Use of Doorway Monitors}

In general, doorway monitors should be used in locations of minimum background and minimum background fluctuation. If circumstances dictate use of a doorway monitor in an area of high background, sufficient shielding should be provided to maintain necessary sensitivity.

\section{a. Attended Doorway Monitor}

(1) If the doorway monitor is attended during use, it need not be equipped with an automatic background updating system, although an automatic system is preferred. When provided, the background update period shall be no greater than $100 \mathrm{~s}$ to minimize false alarms from background variations. 
(2) Before each use* of a doorway monitor not equipped with an an automatic background updating system, the background should be updated. Each individual to be checked should enter the detection area in turn and be required to remain sufficiently long for the device to operate properly.

(3) With the individual being checked in the detection area, an audible and visible alarm should occur if the radiation level exceeds the alarm level.

(4) The doorway monitor should be equipped with a reduced-sensitivity alarm to indicate when a change in an uncontrolled parameter such as increased background reduces the performance below that specified in Sec. C.1.b. The doorway monitor should not be used during such periods of high background. Appendix B [of this draft] gives guidance for determining maximum permissible background levels. The manufacturer shall provide instructions for his specific instrument.

(5) A warning shall be given when the background is reduced enough to indicate a possible equipment malfunction.

\section{b. Unattended Doorway Monitor}

(1) If the doorway monitor is physically unattended, an automatic background update system shall be incorporated into the doorway monitor alarm logic.

(2) Devices such as door interlocks, closed-circuit TV, and occupancy montiors should be used to

- alert the person manning the central alarm station that an individual has entered the secure access passageway and/or is approaching the doorway monitor.

- allow observation of the individual approaching the doorway monitor.

- provide traffic control as appropriate.

(3) An audible and visible alarm should occur in the central alarm station if the radiation level in an occupied doorway monitor exceeds the alarm level.

(4) The doorway monitor should be equipped with a reduced-sensitivity alarm monitored in the central station that indicates when a change in an uncontrolled parameter such as increased background reduces the performance below that specified in Sec. C.1.b. Appendix B [of this draft] gives guidance for determining maximum permissible background levels. The manufacturer shall provide instructions for his specific instrument.

(5) A warning shall be given in the central alarm station when the background is reduced enough to indicate a possible equipment malfunction.

\section{Testing and Calibration}

\section{a. Testing}

Doorway monitors should be tested by passing an appropriate source through the doorway monitor no less frequently than once a day. The source shall be the appropriate amount and type of SNM as specified in Sec. C.1.c of this Guide. The daily test is not meant to do more than provide assurance that the monitor is operating. It may consist of walking the source through the monitor near one of the detectors to see that an alarm sounds.

*"Use" means an individual, or several individuals each in turn, being checked for SNM by the doorway monitor. The maximum period between background updates while the doorway monitor is in use is determined by the stability of local background and may necessarily be shorter than $15 \mathrm{~min}$. 
In addition, a functional performance test should be carried out at least once a week, as discussed in Appendix $\mathrm{C}$ of this Guide.

\section{b. Operating Instructions}

Instructions should be provided to the operator at the doorway monitor, if attended, or at the monitoring point if the doorway monitor is unattended. The instructions should clearly indicate the procedure for use of the doorway monitor. They also should indicate what corrective action is to be taken if a malfunction occurs.

\section{APPENDIX A}

\section{SPECIAL TEST SOURCES}

The substitution of an unaccountable isotopic gamma source for the SNM sources specified in Sec. C.1.c is attractive because it reduces the administrative constraints on source access and storage. The major problem with substitutes is that none are available that have a gamma-ray energy spectrum similar to SNM. Two doorway monitors that use scintillators of different types or of the same type but of different thickness will have different energy responses. Thus, if one chooses a quantity of a particular substitute isotope that gives the same static count rate as a standard source in one monitor, it will not necessarily duplicate the standard count rate in a different monitor. Therefore, a substitute may be specified for a particular monitor, but no universally exact equivalent substitutes are available now.

What can be done is to specify a substitute source that may produce the same count rate, but most likely produces less than the same rate, as the standard source of Sec. C.1.c in any monitor. Such a source may be harder to detect than the standard source. However, if the monitor can detect the substitute, then it also would detect the stronger standard source. Thus, the sensitivity requirements are met.

A particular substitution that is acceptable as stated in the above paragraph is the use of the ${ }^{286} \mathrm{U}$ standard for the ${ }^{280} \mathrm{Pu}$ one. In the commercial monitors available today, the response to the $10-\mathrm{g}{ }^{286} \mathrm{U}$ standard is much lower than that to the $0.5-\mathrm{g}{ }^{288} \mathrm{Pu}$ standard even when the energy window is optimized for ${ }^{285} \mathrm{U}$. Thus, when proper operation of the monitor is demonstrated with the $10-\mathrm{g}{ }^{288} \mathrm{U}$ source, one has the assurance that it also will perform properly for ${ }^{289} \mathrm{Pu}$ monitoring. 


\section{APPENDIX B \\ PROCEDURE FOR DETERMINING MAXIMUM PERMISSIBLE BACKGROUND}

This procedure is one means of estimating maximum permissible background for effective operation of the doorway monitor. The manufacturer shall provide a procedure for his specific instrument.

(1) With the test source at a point of minimum sensitivity, the mean gross counts G should be determined. With the source removed and no longer influencing the monitor, the background $B$ can be determined. The difference $G-B$ is the net source count $S$. For a walk-through monitor, $S=0.8 \times(G-B)$ is a good estimate of the source count that would apply during operation. For monitors requiring the individual to be stationary during the count, $S=G-B$ applies.

The maximum permissible background is that for which the monitor just senses the test source $50 \%$ of the time, or when

$$
G=B_{\max }+S=B_{\max }+n \sqrt{B_{\max }}
$$

where $\mathrm{n}$ is a multiplier. Thus,

$$
\mathrm{B}_{\max }=(\mathrm{S} / \mathrm{n})^{2}
$$

Accuracy in determining $B_{\max }$ requires that a precise determination of $S$ be made; therefore, a determination of $B_{\max }$ made by the manufacturer for typical setup parameters may be as good as one made at the site.

During periods when the background exceeds $B_{\max }$, the sensitivity of the doorway monitor will generally be below that specified as minimum in Sec. C.1.b of this Guide.

Note: This procedure assumes a direct read-out of counts per count interval. If the monitor does not have this feature, the manufacturer should supply a procedure based on the read-out modes of his instrument.

(2) The high-background alarm should be set at the $B_{\max }$ value calculated or at the one provided by the manufacturer. 


\section{APPENDIX C \\ PROCEDURE FOR TESTING SNM DOORWAY MONITORS FOR FUNCTIONAL PERFORMANCE}

Doorway monitors should be tested with an appropriate test source as specified in Sec. C.1.c of this Guide.

The source is carried through the detector area repeatedly at normal passage speed. The source should be positioned to pass through the minimum-sensitivity portion of the monitor as determined below.

Care must be taken, if the source is located on the foot, to avoid placing the source in a stationary position in the monitor. A mark should be made on the floor outside of the monitor so that the source foot can be planted there and then moved through the monitor at normal speed.

The minimum sensitivity points are determined by the geometrical arrangement of the detectors. If not already indicated by the manufacturer, possible locations may be determined from the shape and placement of the detectors. For long rods placed parallel to the doorway sides, the minimum points are likely to be at center top or bottom. For small detectors placed along the doorway sides, the minimum point may be at center top, bottom, or midway between two detectors. If the detectors are widely spaced or shielded, the minimum point may be along the doorway side halfway between. Having located possible sites, one may determine the least sensitive position by performing walk-throughs and noting the minimum results. Where possible, a somewhat stronger source and count-rate measurements can be used to produce a quicker determination of these positions. The locations should be recorded for subsequent test and calibration work.

Having performed the walk-through testing, one can interpret the results with the help of Fig. 1. For example, if 20 passes were made causing 15 alarms, one sees that the corresponding $75 \%$ point lies in the area of detection probability $\geq 50 \%$, and that operation is as specified. However, had only 13 detections occurred, the corresponding $65 \%$ point lies outside the region and, based on this sample size, the operation would be unacceptable.

Note that, in the example given above, the number of passages required may increase the background measured by the monitor. Care should be taken to prevent this by allowing enough time and physical separation of source and monitor between passes or by doing the walk-throughs in small groups with updates on the normal background in between. 


\section{TECHNICAL DATA FOR COMMERCIAL SNM MONITORS}

This section gives information on the commercial SNM monitors as it is available to us from the manufacturers and through DOE testing. The monitors are all SNM doorway monitors except the one that is hand held and is suitable for personnel monitoring in low-traffic areas. We give information on the components, operating requirements, and performance of each instrument, if available.

Some general points on SNM monitor performance that apply to all monitors are used here as an introduction. The monitors detect gamma radiation, both from the natural background produced by radioactive decay occurring in soil, rocks, and air, and from radioactive decay occurring in SNM or other radioisotopes that may be present in the monitor's detection area. Both sources of gamma radiation may be highly variable. The natural background varies geographically from a few microroentgens per hour in some regions, such as the southeastern United States, to as high as $25 \mu \mathrm{R} / \mathrm{h}$ in the Rocky Mountain cities where measurements have been made. The gamma radiation from SNM includes not only the intrinsic radiation from the uranium or plutonium isotopes but also radiation from other radionuclides, particularly from spent or recycled material.

The basic problem is to discern the presence of a significant quantity of SNM from a background that may include natural background, additional radiation from stored SNM, and radiation from other radioactive material or waste. The amount of background detected by the monitor is a primary limitation on its ability to detect a signal. Quantitatively, the magnitude of the statistical variation in the background count $B$ goes as $\sqrt{\mathrm{B}}$. False alarms are minimized by setting the alarm level high enough that the statistical variation of a background is unlikely to exceed it. If we express the alarm level as $B+n \sqrt{B}$, then the false-alarm rate remains reasonably constant as $B$ changes. Now, the signal we would like to detect gives a net count $S$, and the larger $\mathrm{S}$ is, compared to $\mathrm{n} \sqrt{\mathrm{B}}$, the more likely it is to be detected. Thus, the alarm condition is $B+S \geq$ $B+n \sqrt{B}$. If we have to choose a location for an SNM monitor, we should keep in mind that the signal count $S$ remains essentially the same wherever the monitor is located but the background may vary from one location to another. At some place, $n \sqrt{B}$ may increase enough that $S$ is no longer detectable, and therefore, the monitor will no longer have adequate sensitivity. For two DOE-tested monitors in their widest configuration, we estimate this may happen at a background of 30 to $35 \mu \mathrm{R} / \mathrm{h}$. To use a monitor when the background is above this limit, we must increase $S$ by narrowing the doorway width or decrease $B$ by adding shielding where needed. It is best to properly site the monitor so that the backgound is low enough for proper operation. Locating a monitor in a needlessly high background reduces the sensitivity. Also, when high background is from process materials that can be moved about or be shielded from the monitor by traffic, the background can vary enough to cause nuisance alarms.

The commercial monitors will now be discussed individually.

\section{A. IRT Corporation PRM-110 Doorway Monitors}

1. Physical Characteristics and Operational Theory. The PRM-110D detector unit of the IRT monitor, shown in Fig. 2, uses two vertical liquid-scintillator gamma detectors that, with the connecting cable tray, form the doorway. Dimensions of the doorway are $0.76-$ by $1.98-\mathrm{m}$ interior and $1.17-$ by $2.43-\mathrm{m}$ exterior in one configuration. The scintillators are $10.2 \mathrm{~cm}$ in diameter and $2.08 \mathrm{~m}$ long. Scintillator shielding of $0.64 \mathrm{~cm}$ of lead is used to limit the sensitive area of the doorway to that area just beyond the doorway. An infrared light barrier is positioned at the entrance to the doorway to indicate occupancy. Occupancy can also be determined with a door switch or a switch mat. The cable tray also houses the photomultiplier high-voltage supply, the 


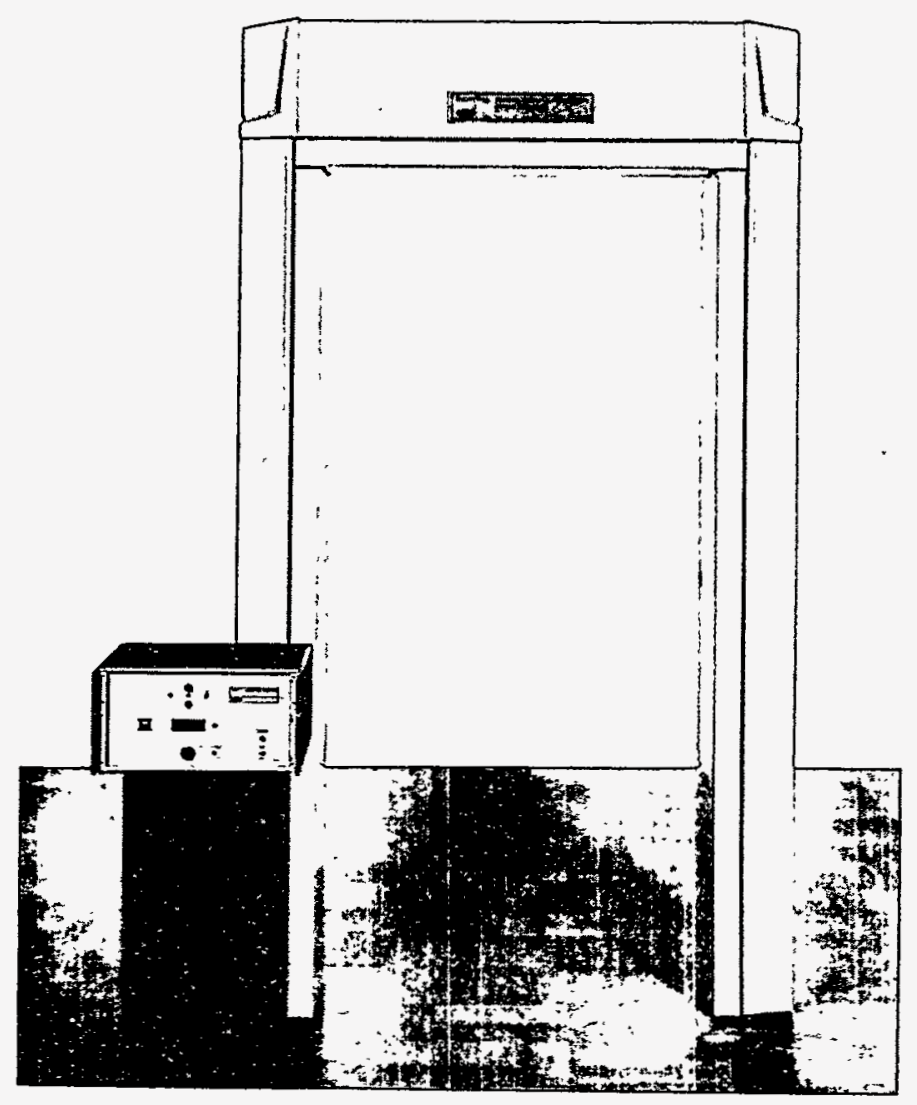

Fig. 2

IRT Corporation PRM-110D detector unit.

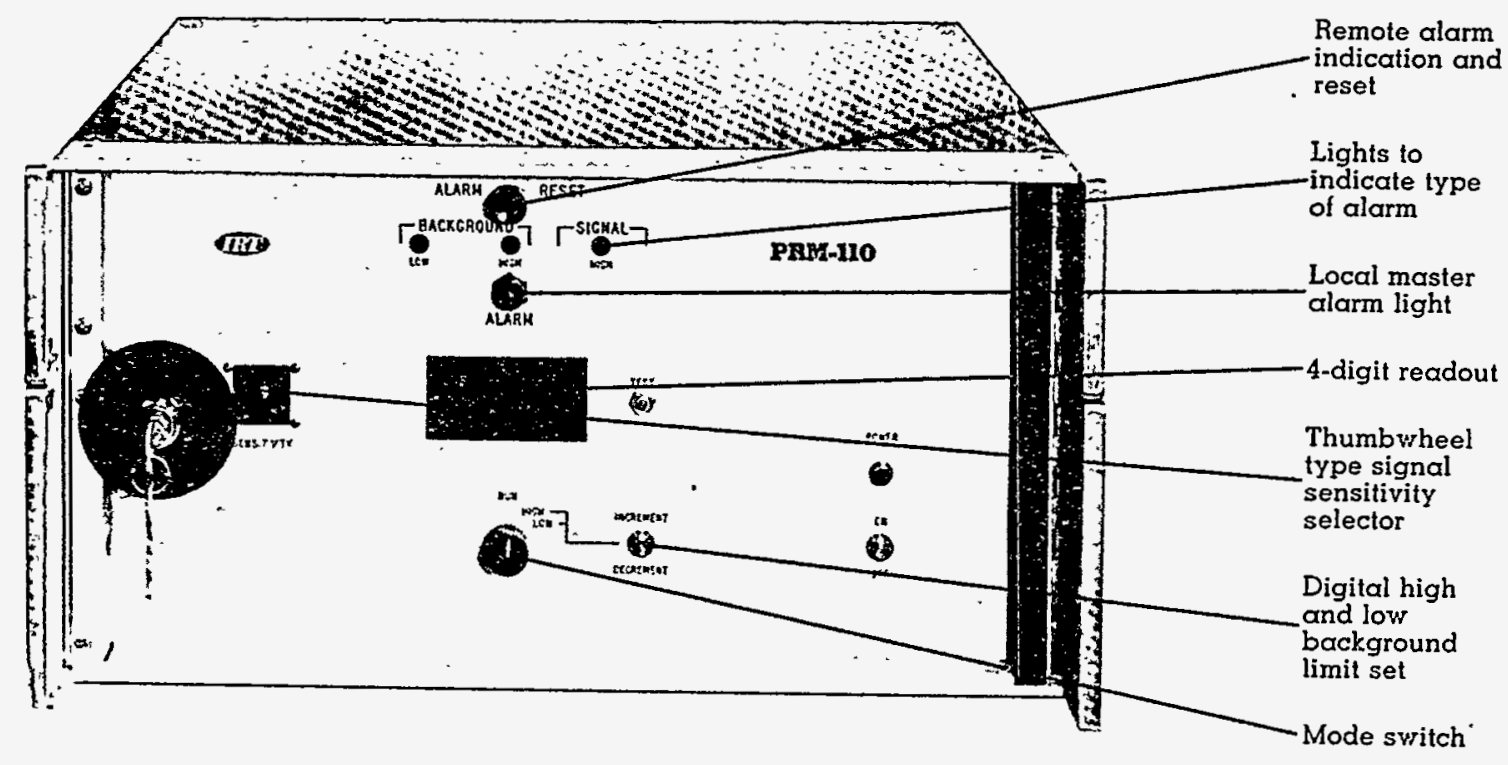

Fig. 3.

IRT doorway monitor control unit. 
signal-conditioning electronics, and a single-channel analyzer (SCA). A PRM-110S detector unit, which is also available, differs by having $2.54 \mathrm{~cm}$ of lead shielding.

The PRM-110C control unit, shown in Fig. 3, provides control, logic, and display functions. Pulses from the photomultipliers are summed, amplified, and examined with an SCA in the detector unit. The SCA logic pulses are then transmitted to the control unit, counted, and processed by the logic unit

The logic unit is a microprocessor that is programmed to operate in two modes, background and signal. During the background mode, the doorway is unoccupied, and the background is continously monitored with count time of $0.25 \mathrm{~s}$. The logic used smooths the background count $\mathrm{B}$ by performing an appropriate sum of fractions of old and new counts to effectively average the background over about $1.5 \mathrm{~s}$. To determine the alarm level, the standard deviation of the raw background is determined from a calculated variance,

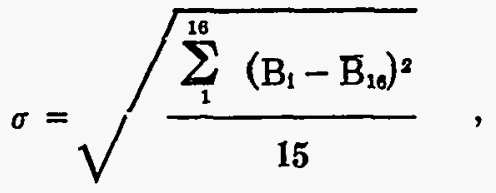

where $\overline{\mathrm{B}}_{18}$ is the mean of the 16 samples used. The sigma is smoothed, and the alarm is obtained by adding a switch-selectable multiple $(M)$ of the smoothed sigma to the smoothed background. The effective alarm update time is governed by the 1.5-s background update time. The four-digit alarm level is displayed on the front panel during the background mode, and the display is updated at 2-s intervals.

The signal mode is entered at interruption of the occupancy monitor. In the signal mode, the count rate during occupancy is compared to the alarm level calculated before occupancy. The display is updated at each of at least five 0.25 -s count periods to show the current signal. This increased display rate is useful as a visual indication of proper operation of the occupancy sensor. The signal mode continues for about $1.5 \mathrm{~s}$ (or more, as adjusted) unless the occupancy monitor is still interrupted, in which case the signal mode continues until about $1.5 \mathrm{~s}$ after occupancy ends. If the smoothed signal exceeds the alarm level, an alarm occurs. A prominent master alarm indicator is turned on along with a smaller high-signal alarm indicator, and relay closures are provided for external remote alarm indicators. The alarm latches and requires an attendant to open the protective transparent door on the front of the control unit and to push a reset button. The protective door is provided to prevent unauthorized access to the front-panel controls and is secured by a key-operated latch.

An alarm condition may also occur in the background mode, because the background is continuously checked against preset high and low count levels. The high level is set on the front panel to the maximum count rate (count per $0.25 \mathrm{~s}$ ) for adequate monitor sensitivity. If the preset level is exceeded, the master alarm, a high-background indicator, and a relay are activated. Once again the alarm latches.

The low-background alarm is set at a count below that expected in normal operation. When the count is less than the low limit, indicating a possible component failure, the master alarm and low-background indicator are turned on and latched.

Both the detector unit and control unit require a local source of $110-\mathrm{V}, 60-\mathrm{Hz}$ power. No emergency power is provided.

Specifications for the IRT PRM-110 as tested by DOE are given in Table I. 
TABLE I

\section{IRT DOORWAY RADIATION MONITOR MODEL PRM- $110^{a}$ FOR ${ }^{288} \mathrm{U}$ OR ${ }^{288} \mathrm{Pu}-{ }^{288} \mathrm{U}$}

Component

Scintillators

Scintillator Shielding

Photomultipliers

Signal-Conditioning Electronics

Control Units
Description and Comments

Liquid scintillators, $10.2 \mathrm{~cm}$ in diameter and $2.08 \mathrm{~m}$ long. In the tested version, one scintillator was about $15 \mathrm{~cm}$ short. Using two equal-length scintillators will improve the sensitivity. Scintillator spacing was $76 \mathrm{~cm}$ (maximum) for use as a ${ }^{285} \mathrm{U}$ monitor and $122 \mathrm{~cm}$ for use as a ${ }^{288} \mathrm{Pu}$ monitor.

Lead $0.32 \mathrm{~cm}$ thick around two-thirds of the scintillator circumference.

RCA 4507. The tubes were operated at about $1700 \mathrm{~V}$ by a Bertan power supply.

Elscint INS-11 amplifier and SCA boards.

The control unit contains a microprocessor programmed for the alarm logic. The programming of the microprocessor was modified during the evaluation. The background-count smoothing routine was changed, and smoothing was added to the signal and sigma values. Also, a larger number of samples were used to determine sigma.

The count time interval used was a nominal $0.2 \mathrm{~s}$ but was measured to be about $0.25 \mathrm{~s}$. The number of signal tests made per passage was five during a 1.25-s counting time. The IRT manual now indicates a 1.5-s count time. Sigma multiplier $\mathrm{M}=7$ or $\mathrm{M}=6$ should be set on the control unit.

As tested by DOE.

2. Installation Requirements and Procedures. Installation of the monitor requires mechanical assembly of the scintillators and connecting tray. Cables for the photomultipliers, power supply, signal-conditioning boards, control unit, occupancy monitor, and the SCA must be properly connected. The light barrier must be optically aligned, if used.

Calibration begins with a procedure to balance the outputs of the two detectors. Each photomultiplier gain is adjusted by varying the high voltage on the photomultiplier to make the output pulse height distributions identical for a given source. This is done by affixing a source alternately to each detector and adjusting a voltage divider until the indicated count rates are the same.

The rest of the calibration procedure sets the optimum window for the SCA. This is done by triggering an oscilloscope with the SCA output while observing the amplified detector pulses. The base level is set just above the noise by using the voltage levels for the lowest observed detector pulses given in the IRT manual. A technique using a source to determine the base level also is outlined.

The calibration procedure should not need to be repeated unless some detector-related component fails. 
Operation of the monitor now requires setting the front-panel-mounted sensitivity thumb switch that enters the sigma multiplier $M$ used to determine the alarm level derived from the background and sigma,

$$
\mathrm{T}=\overline{\mathrm{B}}+(\mathrm{M} / 2) \bar{\sigma} \text {. }
$$

This setting affects the false-alarm rate and detection sensitivity. The high- and low-background alarm levels are also set from the front panel.

Now, the monitor is ready to operate. No further adjustment need be made, and no periodic maintenance is required. The only operator contact is resetting the alarm indicator (an automatic reset option is available to eliminate this requirement).

3. DOE Test Results. Preliminary testing demonstrated the need for several modifications to the monitor. Once acceptable operation was achieved, testing was done from mid-December 1974 to February 1975. During this period, the operation of the monitor was flawless. No other documented reliability data seem to be available.

The DOE sensitivity tests were done with several detector spacings and alarm level settings. The alarm level settings used for ${ }^{285} \mathrm{U}$ were $3 \sigma$ and $3.5 \sigma$, indicated on the front panel as $\mathrm{M}=6$ and $M=7$. Lower values of the sigma multiplier resulted in unacceptably high false-alarm rates, and higher settings resulted in inadequate sensitivity for ${ }^{286} \mathrm{U}$ at the spacing used. Alarm levels up to the maximum of $4.5 \sigma$ were used for ${ }^{289} \mathrm{Pu}$. Note that the sigma multiplier cannot be used for comparison of false-alarm rate or sensitivity with other instruments because a smoothed signal has statistical fluctuations that are less than those in a raw signal. Hence, a $3 \sigma$-alarm level here may result in a lower false-alarm rate than $4 \sigma$-alarm levels produce on other instruments.

In the sensitivity tests, individuals walked through the doorway carrying a $10-\mathrm{g}{ }^{285} \mathrm{U}$ sphere or a $1-\mathrm{g}{ }^{299} \mathrm{Pu}$ sphere (the DOE standard sources) in the location that had been determined to be the least sensitive part of the doorway. For this monitor, the least sensitivity occurs on the center plane between detectors at the head and foot regions. Thus, sources were carried on the head or on the inside of the shoe near the ankle. A normal walking pace was used and, for the foot region, care was taken that the source was neither held stationary nor swung very rapidly through the sensitive region. The walker was instructed to plant the source foot on a marker just outside the sensitive area as he walked through. The effect was for the source to accelerate from a standing start through the sensitive volume. Ten individuals were used in testing sensitivity, so the results are averaged over a wide range of walking speeds and body parameters. Walk-throughs were spaced enough in time to avoid building up source counts in the background and sigma determinations. Results of the sensitivity tests are given in Table II.

Based on the DOE test results, wider spacing would have produced an acceptable monitor only for ${ }^{230} \mathrm{Pu}$ under the test conditions.

False-alarm testing for this monitor requires periodic interrupting of the infrared monitor to get into the signal mode so that signal alarms can be observed. Such interrupting was done infrequently enough to allow complete alarm level updating between interruptions. Here, a rate of 6 interruptions/min was used. Testing was done only at night when, for the most part, only statistical causes of alarms would be present. Results were obtained for two sensitivity settings as shown in Table III.

The indicated alarm rates are adequate to meet the requirement of less than 1 alarm per 8-h period. Note that queuing in the doorway or use of the optional door switch, which could hold the door open for long periods of time, will increase the time the monitor stays in signal mode and will increase the number of false alarms per 8 -h period. 
TABLE II

SENSITIVITY TESTS IN A BACKGROUND OF $25 \mu \mathrm{R} / \mathrm{h}$ FOR THE IRT PRM-110

\begin{tabular}{|c|c|c|c|c|}
\hline Source & $\begin{array}{c}\text { Doorway } \\
\text { Width } \\
\text { (m) } \\
\end{array}$ & $\begin{array}{c}\text { Alarm Level } \\
\text { Setting } \\
(\mathbf{M} / 2) \\
\end{array}$ & $\begin{array}{c}\text { False-Alarm } \\
\text { Rate } \\
\text { (passages) } \\
\end{array}$ & $\begin{array}{c}\text { Smallest Fraction } \\
\text { of Passages } \\
\text { Detected for the } \\
\text { Two Source Positions } \\
\end{array}$ \\
\hline $\begin{array}{l}10-g^{286} U \\
\text { sphere }\end{array}$ & 0.63 & 3.5 & 1 per 4781 & 0.75 \\
\hline $\begin{array}{r}10-g^{235} \mathrm{U} \\
\text { sphere }\end{array}$ & 0.76 & 3.0 & 1 per 1247 & 0.63 \\
\hline $\begin{array}{l}1-\mathrm{g}{ }^{298} \mathrm{Pu} \\
\text { sphere }\end{array}$ & 1.22 & 4.5 & negligible & 1.00 \\
\hline
\end{tabular}

Background as measured with Technical Associates PUG-1 NaI survey meter. Monitor background count rate of 2000 counts $/ 0.25 \mathrm{~s}$.

TABLE III

OBSERVED STATISTICAL FALSE-ALARM

RATE FOR THE IRT PRM-110a

\begin{tabular}{|c|c|c|}
\hline $\begin{array}{c}\text { Sensitivity } \\
\text { Setting } \\
(\mathrm{M} / 2)\end{array}$ & $\begin{array}{c}\text { False-Alarm } \\
\text { Rate }^{b} \\
\text { (per passage) }\end{array}$ & $\begin{array}{l}\text { Observation Time } \\
\text { (h) }\end{array}$ \\
\hline 3.0 & $\begin{array}{l}8.01 \times 10^{-4} \text {, or } \\
1 \text { per } 1247 \text { passages }\end{array}$ & 367.3 \\
\hline 3.5 & $\begin{array}{l}2.08 \times 10^{-4}, \text { or } \\
1 \text { per } 4788 \text { passages }\end{array}$ & 638.3 \\
\hline
\end{tabular}


4. Comments. The basic digital approach of the control unit is itself a very useful feature. The calibration procedure sets the detector-operating parameters, and there is usually no controlunit-related setup involved. The only exception would be when an unusual background count rate required a change in the prescale factor during initial setup. After initial setup, no logic unit changes are required with even large changes in background; whereas analog units may require a resetting procedure for large changes in background.

The monitor is basically an indoor instrument, because no weather protection is provided and the operating temperature range does not extend below freezing. There are no other installation restrictions.

During the 2-month DOE test period, the monitor was stable enough to operate without attention. Response to real background variations was very rapid because of the 1.5-s effective time constant of the background algorithm.

\section{B. National Nuclear Corporation DM-2 Doorway Monitor}

1. Physical Characteristics and Operational Theory. The National Nuclear Corporation (NNC) Model DM-2 doorway monitor, shown in Fig. 4, consists of two solid-slab scintillator gamma-ray detectors bridged by a box containing an ultrasonic occupancy monitor and the preamplifier bases for the photomultipliers. The scintillator slabs cover the full height and width of the doorway sides. Gamma-ray shielding is provided by lead on the three sides of the scintillator external to the doorway. The ultrasonic occupancy monitor inside of the sheet metal bridge is collimated by a hole in the bridge that limits its field of view. The control unit consists of a Nuclear Instrument Module (NIM) bin with a commercial high-voltage power supply, an amplifier-SCA, a rate meter, and an NNC analog alarm logic module.

Pulses from the photomultipliers are conditioned in preamplifier bases in the doorway. Pulses are then transmitted to the control unit, summed, amplified, and processed by an SCA. The SCA logic pulses are fed to a rate meter, and the rate meter recorder output is used by the alarm logic module. The alarm module input is monitored by three separate analog circuits that alarm on high background, low background, and high signal ("fissile" alarms). The high- and lowbackground alarm circuits compare the input signal from the rate meter with a fixed reference. The high- and low-background alarm points are varied by front-panel potentiometers, which in turn vary the fixed references that are one side of voltage comparators. The high-background level must be set at the background rate at which false alarms in the fissile loop become too frequent; the low-background alarm point is set at the level where sensitivity is inadequate.

The fissile alarm circuitry has signal and reference voltage levels that are obtained from $\mathrm{R}-\mathrm{C}$ circuits with different time constants. In the version tested by DOE, a 20-s time-constant circuit was used for the background reference level and a 0.4-s time-constant circuit was used for the signal. The response of the short-time-constant circuitry to a change in signal that might be introduced by walking through the monitor with a gamma source is fairly rapid. The long-timeconstant reference circuit responds to the change more slowly. As in the background monitors, an alarm occurs in the fissile alarm circuitry when the signal level exceeds the reference by more than a fixed offset. Variation of sensitivity is achieved by an input voltage divider mounted on the front panel, which varies the magnitude of the input in relation to the fixed offset in the voltage comparator.

Alarm indication for the three alarm conditions is given by indicator lights next to the appropriate potentiometer, an audible alarm, and a relay closure. The internal alarms are not latching, and reset is automatic. The doorway monitor operates continuously, but the cccupancy monitor is used to enable the audible alarm and relay closure. Thus, for fissile alarms, false 


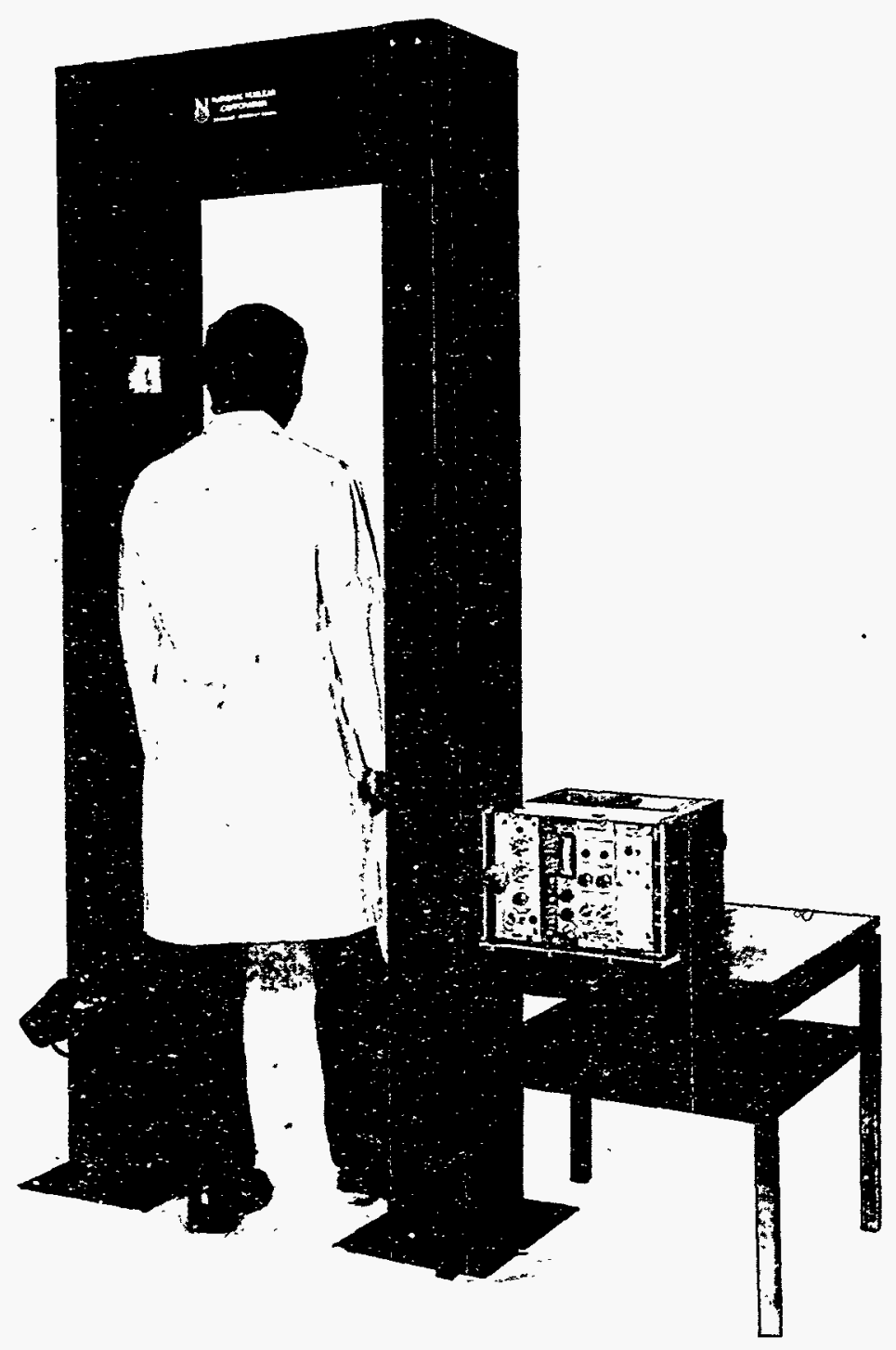

Fig. 4.

National Nuclear Corporation DM-2 doorway monitor.

alarms may occur when the monitor is unoccupied, but there is no audible signal or relay closure that occurs when the doorway is occupied.

A count read-out is provided by the rate-meter display. The rate-meter time constant varies with count rate and does not necessarily indicate the background or signal levels used by the logic module, but it is useful for routine monitoring of detector performance. Because of the shape of the detector shielding, the sensitive volume of the monitor is mostly inside the doorway, where the occupancy monitor is located. The ultrasonic monitor is centrally mounted so that the doorway monitor operates as well for passage in one direction as in the other.

Specifications for the DM-2, as tested by DOE, are given in Table IV. Differences between the one tested and the present version are slight and should not affect performance. 
TABLE IV

\section{NATIONAL NUCLEAR CORPORATION DM-2 DOORWAY MONITOR}

\begin{tabular}{|c|c|}
\hline Component & Description and Comments \\
\hline Scintillator & $\begin{array}{l}\text { Plastic scintillator, Nuclear Enterprises ty } \\
\text { NE- } 102 \text { with the photomultipliers position } \\
\text { above and } 76 \mathrm{~cm} \text { between the detectors. }\end{array}$ \\
\hline Photomultipliers & RCA 4518 operated at $1500 \mathrm{~V}$. \\
\hline Control Units & $\begin{array}{l}\text { The control unit consisted of the following } \\
\text { NIM bin and NIM modules. }\end{array}$ \\
\hline Bin & Tennelec TC 909 \\
\hline $\begin{array}{l}\text { High-Voltage } \\
\text { Power Supply }\end{array}$ & Power Designs AEC 315B \\
\hline Preamplifier ${ }^{\mathfrak{b}}$ & Tennelec TC 145 \\
\hline Amplifier & Tennelec TC 216 amplifier with SCA \\
\hline Rate Meter & ORTEC 441 \\
\hline Logic Unit & NNC doorway monitor alarm module \\
\hline Occupancy Monitors & $\begin{array}{l}\text { In addition to the ultrasonic } \\
\text { monitor, a light link was provided. }\end{array}$ \\
\hline
\end{tabular}

2. Installation Requirements and Procedures. Installation of the monitor requires erecting the detector columns (about $160 \mathrm{~kg}$ each) and attaching the connecting bridge between them. The preamplifier bases, amplifier, occupancy monitor, high-voltage power supply, and logic unit must be properly connected together. Sensitivity adjustment of the ultrasonic occupancy monitor may not be necessary because it can be preset before it is shipped from NNC.

In the first step of monitor calibration, the two detector outputs are balanced by observing the count rate indicated on the rate meter as a source is counted in one detector at a time. A slight gain adjustment is made by varying the focus voltage on the photomultiplier base until the detector count rates are equal.

Next, the SCA window must be set to optimize the monitor sensitivity for a specific material to be monitored or for ${ }^{28 s} U$. The figure of merit to be optimized is $S^{2} / B$, where $S$ is the net signal from the SNM test source and B is the background count. The figure of merit is maximized by adjusting the SCA window lower level and width, while making source-in and source-out count-rate measurements using the rate meter, until the SCA window is found that gives the maximum figure of merit. 
Now the rate-meter range must be adjusted to allow the operating background to fall at a convenient point on the meter.

The final adjustment made in calibration is the fissile potentiometer setting of the logic module. This adjustment varies the magnitude of the input in relation to the fixed offet of the voltage comparator in the fissile alarm circuit. If we denote the pertinent voltages in the shortand long-time-constant circuits as $v_{\mathbf{s}}(t)$ and $v_{1}(t)$ and the fixed offset as $v_{\ell}$, then the alarm condition is

$$
v_{8}(t)-v_{1}(t) \geq v_{\ell}
$$

The effect of the input voltage divider, called the fissile potentiometer, reduces the magnitude of both $v_{B}$ and $v_{1}$, and gives the adjusted alarm condition

$$
k\left[v_{s}(t)-v_{1}(t)\right] \geq v_{r} \text {. }
$$

The constant $\mathrm{k}$ must be changed by varying the fissile potentiometer until $\mathrm{k}$ is large enough that the monitor will detect passage of the appropriate SNM source but is small enough that the false-alarm rate is acceptable. One can easily reach a starting point in setting this control; however, long-term measurements are required to determine the false-alarm rate adequately. Provision is made to allow use of a strip chart recorder to record alarms during periods when only statistical alarms are expected and the monitor is not in use. If the false-alarm rate is excessive, the fissile potentiometer setting must be reduced, the sensitivity must be redetermined, and a new false-alarm rate must be determined.

Calibration should not need repeating except when a major change in background occurs; then the fissile potentiometer setting procedure must be repeated. If the change is enough to necessitate changing the rate-meter range, then the rate-meter output voltage change requires that the logic module be recalibrated. Other increases in background may be large enough to affect the false-alarm rate, though they do not require a rate-meter range change. The magnitude of statistical variation in the voltage difference at the comparator increases with background, and from the alarm condition

$$
k\left[v_{B}(t)-v_{1}(t)\right] \geq v_{\ell},
$$

we see that the effect of larger voltages is the same as an increase in $\mathrm{k}$, which represents the fissile potentiometer setting. Thus, in this monitor, an increase in background increases the false-alarm rate and the sensitivity. Conversely, when the background is less than that when the monitor was calibrated, the sensitivity is reduced.

Here, we should emphasize that the effect of background changes on sensitivity discussed are simply a result of variations about a set of parameters fixed in the calibration procedure. When the monitor calibrated in two different backgrounds gives identical false-alarm rates, its sensitivity is lower in the higher background, as with other instruments.

The high-level alarm potentiometer on this instrument is set at the level at which the fissile false-alarm rate becomes unacceptably high. The chosen upper limit alarm point can be tested by placing a gamma source near the detector to raise the background to the chosen rate and then measuring the fissile false-alarm rate.

The lower limit alarm level on this instrument should be set at the level at which the sensitivity becomes inadequate. In the DOE tests, a setting at $10 \%$ reduction in background was used, which maintained adequate sensitivity. Larger background reductions were not experienced.

Now the monitor is operational. No operator contact is required, and no periodic maintenance is prescribed. 
3. DOE Test Results. Following an initial period during which some component substitutions were necessary, the evaluation was completed in about 1 month. Although other reliability information is not documented, no problems were experienced during the evaluation period.

The DOE sensitivity tests were done with the scintillators at $76 \mathrm{~cm}$, the widest spacing available from NNC then. In the tests, several individuals walked through the doorway carrying the appropriate source in the previously determined least sensitive region of the doorway. For this monitor, the least sensitivity is on the median plane between detectors at the foot of the doorway. The sensitivity is better in the head region near the photomultipliers because the light pulse is attenuated some while traveling the length of the scintillator, causing some floor-level pulses to fall below the SCA windows. Sources were carried through the doorway inside the shoe or attached to the shoe on the inside of the ankle, using the same test program as detailed for the IRT monitor. Results are given in Table V. These tests were run with a fissile potentiometer setting of 2.0 (monitor count rate of 5500 counts/s). The time constants were 20 and $0.4 \mathrm{~s}$. The rate meter was set at $10 \%$ fractional standard deviation and operated on $10 \mathrm{k} \times 1$ range.

The sensitivity achieved for ${ }^{28} \mathrm{Pu}$ indicates that increased doorway width, reduced scintillator volume, or reduced fissile potentiometer setting and associated false-alarm rate could have been used to obtain acceptable performance as a monitor only for ${ }^{239} \mathrm{Pu}$ under the test conditions. Table $\mathrm{V}$ also indicates that, at a reduced doorway width, adequate performance as a ${ }^{288} \mathrm{U}$ or ${ }^{289} \mathrm{Pu}$ monitor could have been achieved with smaller scintillators or with reduced fissile potentiometer setting and accompanying false-alarm rates.

The false-alarm rate for this monitor was measured at night when only statistical alarms are expected. Testing was continuous because the background update is continuous and unaffected by occupancy. The occupancy monitor is used to gate the audible alarms and fissile alarm relay closures, and therefore the false-alarm rate per passage is the product of the hourly rate observed and the fraction of an hour that the doorway monitor is occupied per passage. There are two occupancy monitors on this doorway and each has its own characteristic occupancy time. During a passage, the ultrasonic monitor remains in the occupied condition longer, estimated at $1 \mathrm{~s}$. The results of false-alarm (occupied alarm) tests calculated for a 1-s occupancy time are shown in Table VI. The indicated rates are low enough to be reasonable under the DOE standard even with the increase in false alarms as the background approaches the high-background alarm level. The conditions for these tests were: fissile potentiometer $=2.0$, background rate $=5500 / \mathrm{s}$, time constants $=0.4$ and $20 \mathrm{~s}$, rate meter on the $10 \mathrm{k} \times 1$ range, and $10 \%$ fractional sigma.

TABLE V

\section{SENSITIVITY TESTS IN A BACKGROUND OF $25 \mu \mathrm{R} / \mathrm{h}$ FOR THE NNC DM-2a}

\begin{tabular}{|c|c|c|c|}
\hline Source & $\begin{array}{l}\text { Doorway } \\
\text { Width } \\
\text { (cm) }\end{array}$ & $\begin{array}{c}\text { False-Alarm } \\
\text { Rate } \\
\text { (passages) }\end{array}$ & $\begin{array}{c}\text { Fraction of } \\
\text { Passages } \\
\text { Detected }\end{array}$ \\
\hline $\begin{array}{r}10-g^{235} \mathrm{U} \\
\text { sphere }\end{array}$ & 76 & 1 per 4537 & 0.66 \\
\hline $\begin{array}{l}1-\mathrm{g}^{280} \mathrm{Pu} \\
\text { sphere }\end{array}$ & 76 & 1 per 4537 & 1.00 \\
\hline
\end{tabular}

TABLE VI

\section{FALSE-ALARM RATE MEASURED DURING NONWORK HOURS FOR THE NNC DM-2}
False-Alarm Rate (per passage)
$2.2 \times 10^{-4}$, or 1 per 4537 passages

aCalculated for a 1-s occupancy time per passage.

Background as measured with Technical Associated PUG-1 NaI survey meter. Monitor background count rate of 5500 counts/s. 
4. Comments. The analog nature of the logic unit required some lengthy descriptions in this report; however, we should not conclude that routine operation need be any more complicated than that for a digital unit. The single important difference, which will be apparent to the user, is the need to determine the false-alarm rate. Once this is determined in the initial setup period of perhaps a few days, further determination should not be necessary except when a component fails or the background changes greatly.

During the month-long DOE tests, the monitor was stable enough to operate without attention. The only installation restriction seems to be that it be used indoors or that other weather protection be provided.

\section{Tom Scurry Associates PM-203 Doorway Monitor}

1. Physical Characteristics and Operational Theory. The Tom Scurry Associates (TSA) PM-203 detector unit consists of an array of eight small NaI scintillators, each $5.08 \mathrm{~cm}$ in diameter and $2.54 \mathrm{~cm}$ thick, with four on each side of the doorway. Vertical spacing between scintillators is $55 \mathrm{~cm}$, with the top and bottom scintillators about $15 \mathrm{~cm}$ from the floor and ceiling of the doorway. The detector enclosure used to form the doorway is shown in Fig. 5; the spacing between the sides is $76 \mathrm{~cm}$ and the height about $196 \mathrm{~cm}$. In addition to the scintillators, the enclosure contains the photomultiplier tubes, bases, and lead shielding used for collimation of the scintillators. An occupancy monitor, also a functional part of the doorway, includes switch mats, ultrasonic motion detectors, and an infrared light link. The control unit, shown in Fig. 6, contains the signal-conditioning electronics, power supplies, and logic unit.

The logic module is a Rocky Flats design manufactured by TSA. Called a digital updating comparator (DUC), the logic unit uses the SCA logic pulses as input and, in the unoccupied state, simply accumulates background counts in end-to-end 20 -s intervals. When the monitor is occupied, the DUC begins a series of 1-s-long signal counts that is compared with an alarm level derived from the most recent stored background. The alarm level used is the mean background count for a 1-s count. The signal count mode persists until $\sim 1 \mathrm{~s}$ after the occupancy ceases when the background accumulation resumes. Should an alarm occur, an audible and visual indicator is activated and latched.

Low- and high-background checks in this instrument are made by comparing the background count rate to switch-selectable alarm levels. Here an alarm latches a specific visual indicator and activates relay closure.

Specifications for the PM-203 as tested by DOE are given in Table VII.

2. Installation Requirements and Procedures. When the unit is assembled and interconnecting cables are installed, a calibration procedure begins. The initial settings of the photomultiplier high voltage and the amplifier gain are adjusted by observing the amplifier output on a multichannel analyzer when a $1-\mu \mathrm{Ci}{ }^{37} \mathrm{Co}$ source is taped to one of the scintillators. When an overall gain is achieved that will allow a suitable display of the ${ }^{87} \mathrm{Co}$ signal, the source is attached to each of the other scintillators in turn, and the gain on that photomultiplier tube base is adjusted to equalize the ${ }^{87} \mathrm{Co}$ spectra. When the energy calibration procedure is completed, the SCA window is set either to tabulated values given in the TSA operating manual, or if a ${ }^{283} \mathrm{U}$ source is available, it can be set to an optimum window by following a procedure outlined in the manual. The energy window used is 70 to $220 \mathrm{keV}$.

Operation of the monitor requires setting the front-panel-mounted sigma selector to 4 and the high- and low-background alarm switches. Operator interaction after that should be limited to resetting alarm indicators. 


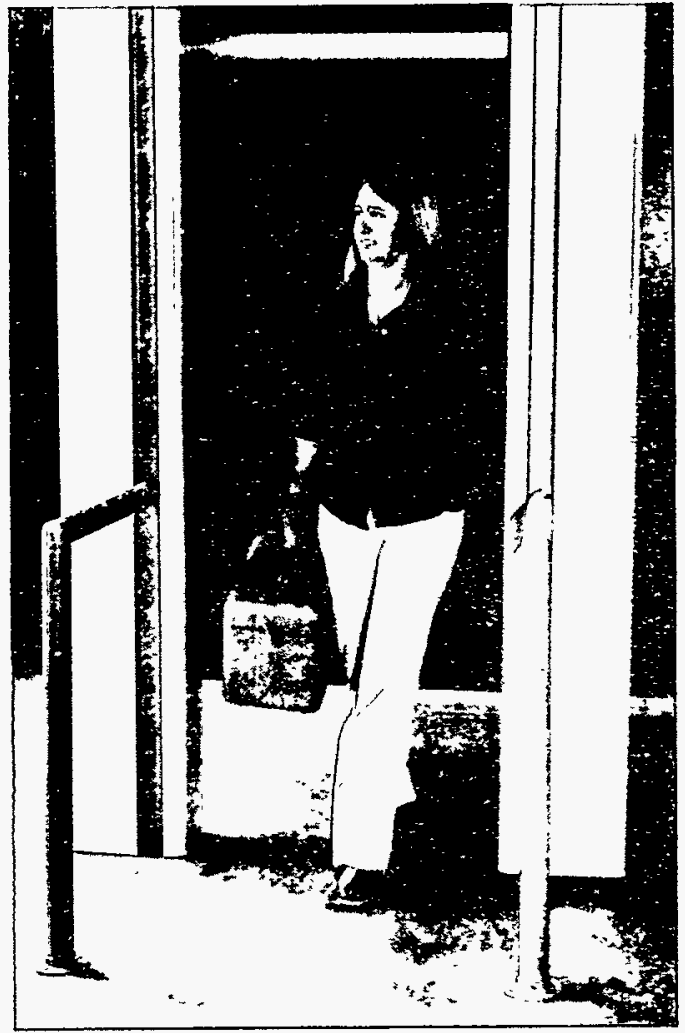

Fig. 5.

Tom Scurry Associates PM-203 detector enclosure.

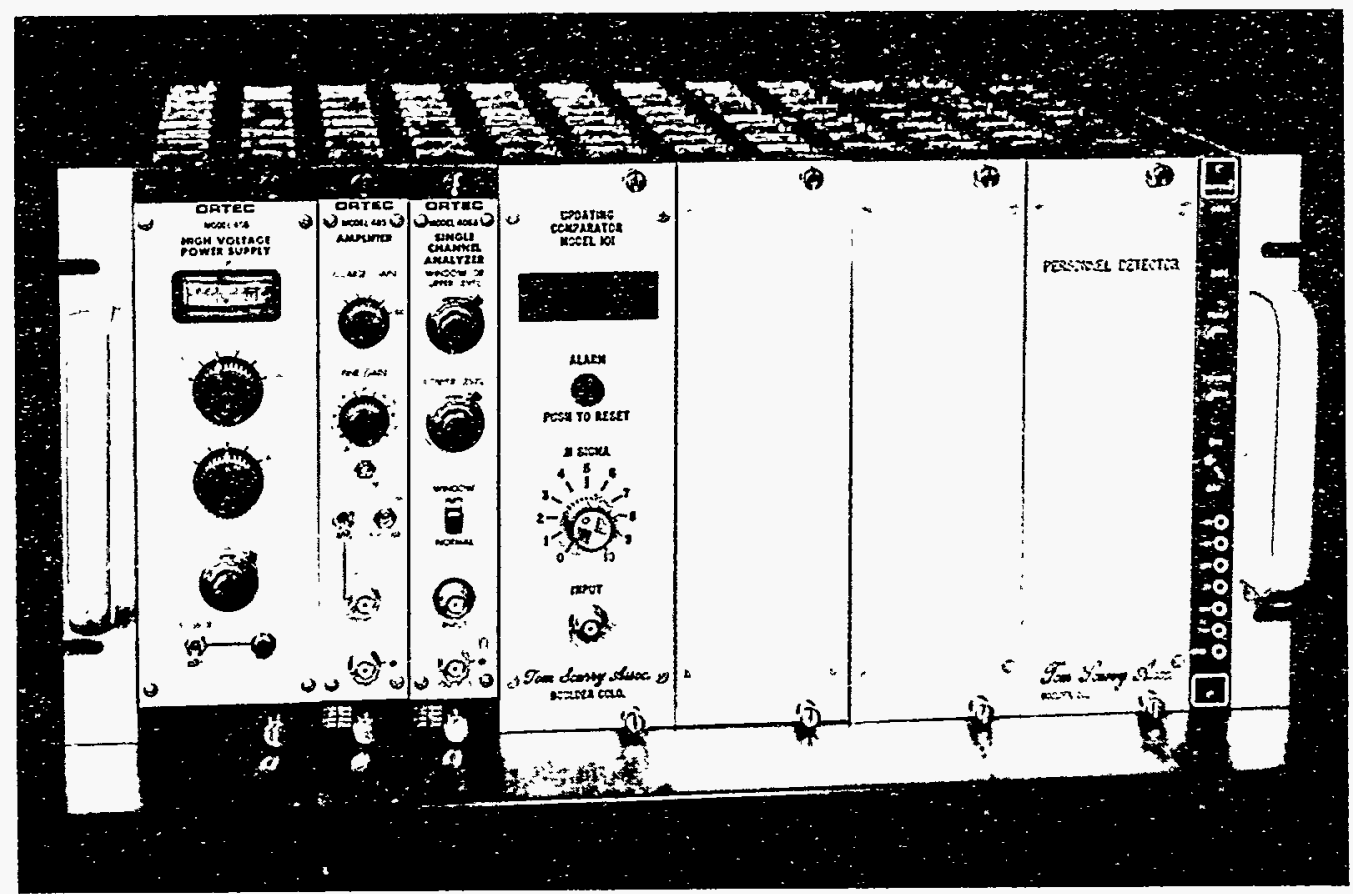

Fig. 6.

Control unit of the PM-203. 
TABLE VII

TOM SCURRY ASSOCIATES PM-203 DOORWAY MONITOR ${ }^{\mathrm{a}}$

FOR ${ }^{285} \mathrm{U}$ OR ${ }^{288} \mathrm{Pu}-{ }^{288} \mathrm{U}$

\begin{tabular}{|c|c|}
\hline Component & Description and Comments \\
\hline Scintillators & $\begin{array}{l}\text { Eight Bicron integral NaI scintillator/ } \\
\text { photomultipliers model } 2 \mathrm{M} 1 / 2 \text {. Each crystal is } 5.08 \mathrm{~cm} \\
\text { in diameter and } 2.54 \mathrm{~cm} \text { thick with centers located } \\
\text { vertically } 15 \mathrm{~cm}, 70 \mathrm{~cm}, 125 \mathrm{~cm} \text {, and } 180 \mathrm{~cm} \text { above the } \\
\text { bottom of the cabinet. The horizontal spacing between } \\
\text { the scintillators was } 76 \mathrm{~cm} \text { for the combined }{ }^{285} \mathrm{U} \\
\text { and }{ }^{299} \mathrm{Pu}-{ }^{288} \mathrm{U} \text { monitoring and } 122 \mathrm{~cm} \text { for }{ }^{289} \mathrm{Pu} \text {-only } \\
\text { monitoring. }\end{array}$ \\
\hline Scintillator Shielding & $\begin{array}{l}\text { Lead } 0.32 \mathrm{~cm} \text { thick wrapped around } \\
\text { each photomultiplier tube as a cylinder and a } \\
15-\mathrm{cm} \text { square sheet that forms a cone centered } \\
\text { on each scintillator. }\end{array}$ \\
\hline Updating Comparator & N SIGMA switch set to 4 \\
\hline Occupancy Monitor & Infrared light link \\
\hline High-Voltage Power Supply & ORTEC 456 set at $1100 \mathrm{~V}$ \\
\hline Preamplifier & ORTEC 113 \\
\hline Amplifier & ORTEC 485 \\
\hline SCA & ORTEC 550 \\
\hline
\end{tabular}

3. DOE Test Results. The TSA monitor was received and set up in January 1977. Preliminary tests indicated that the detectors were too tightly collimated by the lead shielding cones to view a source near the side of the doorway halfway between two detectors. The problem was corrected by shimming the lead shielding away from the cabinet surface and bending the shielding slightly. Then sensitivity anywhere along the doorway sides was slightly greater than at the top center of the doorway. During the evaluation period, a single short interruption of the evaluation occurred because one of the light-link receivers failed.

Sensitivity tests for ${ }^{286} \mathrm{U}$ were done with the doorway width at $76 \mathrm{~cm}$ and the N SIGMA switch setting at 4 . Preliminary tests indicated adequate sensitivity for ${ }^{289} \mathrm{Pu}^{288} \mathrm{U}$ at TSA's advertised $122-\mathrm{cm}$ width, but in the $21-\mu \mathrm{R} / \mathrm{h}$ test background, adequate sensitivity for ${ }^{286} \mathrm{U}$ with a 4 -sigma alarm level setting was not achieved until the spacing was reduced to $76 \mathrm{~cm}$.

First, static source measurements were used to determine the low-sensitivity regions in the monitor. These are, with the lowest first: the top center of the doorway at the height of the cabinet top; the bottom center at the floor; and the regions halfway between detectors at the sides 


\section{TABLE VIII}

\section{SENSITIVITY TEST IN A BACKGROUND OF $21 \mu \mathrm{R} / \mathrm{h}$ FOR THE TSA PM-203 ${ }^{\mathrm{a}}$}

\begin{tabular}{|c|c|c|c|c|}
\hline Source & $\begin{array}{l}\text { Doorway } \\
\text { Width } \\
\text { (cm) }\end{array}$ & $\begin{array}{c}\text { N SIGMA } \\
\text { Switch }\end{array}$ & $\begin{array}{c}\text { Observed } \\
\text { False-Alarm } \\
\text { Rate } \\
\text { (passages) }\end{array}$ & $\begin{array}{c}\text { Minimum } \\
\text { Detection } \\
\text { Probability } \\
\text { for Source } \\
\text { Positions } \\
\text { Used }\end{array}$ \\
\hline $\begin{array}{r}10-g^{285} U \\
\text { sphere }\end{array}$ & 76 & 4 & 1 per 3850 & 0.63 \\
\hline $\begin{array}{l}1-g{ }^{289} \mathrm{Pu} \\
\text { sphere }\end{array}$ & 122 & 4 & 1 per 3850 & 1.00 \\
\hline
\end{tabular}

"Background measurements were carried out using a Reuter-Stokes RS-111
environmental monitor. Monitor background count rate of 385 counts/s using
a SCA window optimized for ${ }^{235} \mathrm{U}$.

of the doorway. The sensitivity for detection was then determined by several individuals walking through the monitor with a source attached so that it passes through a region of lowest sensitivity. Thus, sources were carried on the head, on the inside of the shoe near the ankle, or on the side of the body at waist or calf. The test program was the same as detailed for the IRT monitor. Results of the sensitivity tests are given in Table VIII.

The disparity in doorway widths for the uranium and plutonium sources in Table VIII is common to all doorway monitors. Static measurements on this monitor indicate that at 76-cm spacing the ${ }^{289} \mathrm{Pu}$ sensitivity would be adequate to detect a $0.25-\mathrm{g}{ }^{289} \mathrm{Pu}$ sphere at the 4-sigma setting.

False-alarm testing was done at night and on weekends when there should be little interference from changing background. The light link was interrupted with a rotating shutter for a period in which about 29 of the 1-s counts were made, then about $24 \mathrm{~s}$ was allowed for the background to update. The alarm relay closure was used to record false alarms and to actuate an electromechanical device that operated the reset button. Results are given in Table IX.

The results agree with alarm rates calculated using the Poisson distribution and a truncated square root. The interval between alarms was also recorded, and the distribution of intervals was consistent with the alarm probability determined. The 3-sigma setting alarm rate is too high. At 4 sigma, the indicated alarm rate per passage is adequate, even at a very high traffic rate. Note that if the monitor were set up for two-way traffic, the occupied state would persist longer and more 1-s samples would be collected. The alarm probability per passage increases directly with the number of samples made in one passage. We might expect a doubling of the alarm frequency with two-directional operation; here that rate would still be acceptable.

4. Extrapolations from the DOE Tests. To estimate what increased doorway widths might be used in low-background environments and still maintain the sensitivity achieved during this evaluation, a series of static measurements were made. It was determined that the ratio of the mean source counts accumulated during a walk-through to a static count with the source in the same position was 0.57 for the head region of the doorway. The factor 0.57 was used with static 
TABLE IX

\section{OBSERVED STATISTICAL FALSE-ALARM RATE FOR THE TSA PM-203}

\begin{tabular}{|c|c|c|}
\hline $\begin{array}{l}\text { N SIGMA } \\
\text { Switch } \\
\end{array}$ & $\begin{array}{c}\text { False-Alarm } \\
\text { Rate }^{\mathrm{a}} \\
\text { (per passage) }^{\text {pasage }}\end{array}$ & $\begin{array}{l}\text { Observation } \\
\text { Time } \\
\text { (h) }\end{array}$ \\
\hline 3 & $\begin{array}{l}4.2 \times 10^{-3}, \text { or } \\
1 \text { per } 238 \text { passages }\end{array}$ & 15 \\
\hline 4 & $\begin{array}{l}2.60 \times 10^{-4} \text {, or } \\
1 \text { per } 3850 \text { passages }\end{array}$ & 725 \\
\hline
\end{tabular}

${ }^{a}$ Two 1-s count intervals were processed at each passage.

measurements of the source positioned in the head region at several doorway widths to determine an equivalent walk-through source count at each width. This source count was used to calculate the maximum background count rate where the monitor would have the same sensitivity as measured in the evaluation. The results are shown in Fig. 7. To use Fig. 7 to estimate a maximum width for a new location, use 18.3 counts/s for each microroentgen per hour background if an accurate background measurement has been made.

5. Comments. The performance of this monitor during the evaluation period was exceptionally good. The monitor functioned properly when set up and continued to operate with only the one failure already mentioned.

Mechanical setup of the monitor required about 1 man-day. The user must mount the detectors in the cabinets (they are shipped separately for mechanical and thermal protection) and then provide support for the cabinets, light-link components, and cables. A barrier across the cabinet top has to be provided in a working installation and was assumed to be there during this evaluation. The height of the barrier would be only $188 \mathrm{~cm}$ with the cabinet resting on the floor. However, there was more sensitivity in the foot region than in the head region, so the cabinet bottom was raised $7.6 \mathrm{~cm}$ above the floor, putting the head barrier at $195 \mathrm{~cm}$. When sensitivity tests were repeated, the results were acceptable.

Calibration of the unit requires setting individual gain and focus adjustments on each of the eight detectors and then determining the optimum SCA window. The initial calibration can take an hour or two but thereafter, checking the calibration is quite rapid. A preliminary setup at the factory can be a big help and presumably is done. However, none of the locking adjustments had been locked in the tested unit, and the adjustments changed in packing and shipping.

The use of eight small $\mathrm{NaI}$ detectors in this monitor has several important consequences. One effect of the individual detectors is that the sensitivity varies a great deal on the doorway sides between detectors. As a result, care must be taken that the discrete detector shielding is properly designed and is in the proper place so that sensitivity is not lost.

By using small, high-efficiency $\mathrm{NaI}$ detectors, the background count rates are low enough that the 4-sigma trip level is a large fraction of the background. For example, with a TSA PM-203 background of 386 counts/s, the 4-sigma alarm point is 465 counts/s, or $20 \%$ above background. 


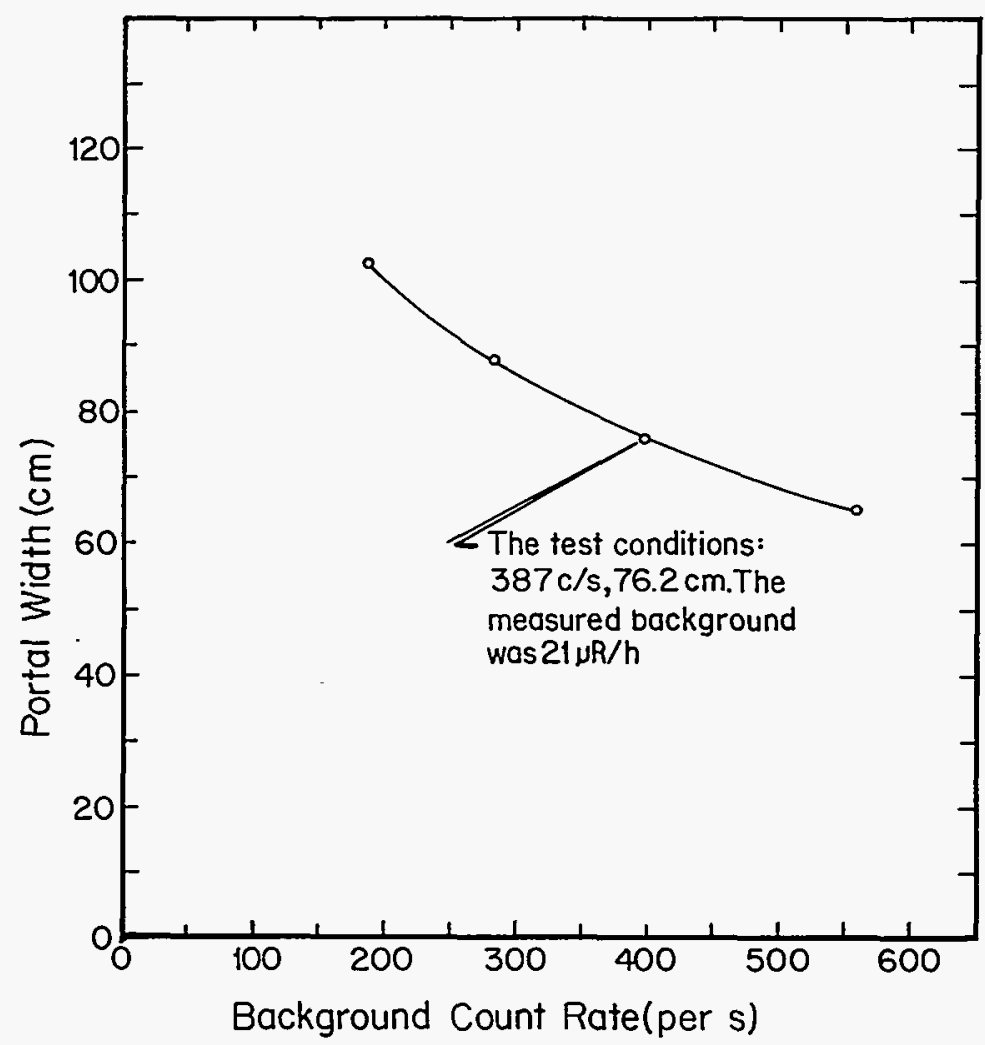

Fig. 7.

Maximum count rate vs portal width for the PM-203 doorway. The optimum window for ${ }^{295} U$ is assumed.

Another result of the low count rate is that the false-alarm rate varies with count rate. It is usually assumed that the normal distribution can be used to describe the distribution of sample counts in a doorway monitor, and thus a constant false-alarm rate with background occurs. Here it is necessary to use the Poisson distribution to accurately calculate the frequency of 4-sigma deviations. The result is a variation that corresponds to about a $25 \%$ increase over the test results in false-alarm rate at a monitor background of 183 counts/s $(10 \mu \mathrm{R} / \mathrm{h})$ to a $25 \%$ reduction at 551 counts/s $(30 \mu \mathrm{R} / \mathrm{h})$.

The only installation restriction seems to be that the NIM bin be used indoors or that weather protection be provided.

\section{National Nuclear Corporation Hand-Held Monitor HM-3}

Hand-held monitors for SNM can serve the same function as SNM doorway monitors. The use of hand-held monitors does differ from the use of doorways because operator action is required to scan the person being searched. The manual scanning procedure changes the importance of some instrument parameters that were emphasized in discussing doorways. For instance, a false alarm in a doorway monitor is important and triggers a response such as a repeat of the walk-through or a manual search. For the HM-3 hand-held monitor, a single false alarm that might occur from 
statistical variation is much less important. The response to an alarm during a scan is to move the instrument closer and more slowly over the suspected region. Lack of further alarms indicates a false alarm and little time is wasted. Thus, although a false-alarm rate from statistical variations of 1 alarm/8-h shift for a doorway monitor is required, this hand-held monitor can conveniently be operated at an alarm rate, from statistical variation, perhaps as high as 1 alarm $/ 15 \mathrm{~s}$. Also, in doorway monitors, alarms are suppressed when the monitor is unoccupied, but for this hand-held monitor, the alarms are not inhibited and are useful for telling the operator that he indeed has a reasonable alarm level stored in the instrument. These differences, and others that may appear later, make a direct comparison of sensitivity between hand-held and doorway monitors of little value. The hand-held monitor does not compete with the doorway monitor except perhaps as a low-cost monitor for use in a low-traffic location. The primary uses of the handheld monitor are for secondary searches of suspected individuals and for searching vehicles, packages, and hand baggage.

1. Physical Characteristics and Operational Theory. The HM-3 was developed at the Los Alamos Scientific Laboratory (LASL), where it was designated HSS 1050. The NNC version, which differs slightly but appears similar to the HSS 1050', is shown in Fig. 8. The unit is about 21 $\mathrm{cm}$ long by $13.5 \mathrm{~cm}$ wide, and including the handle, its height is about $16.5 \mathrm{~cm}$. The mass is 1.7 $\mathrm{kg}$.

The unit contains a $\mathrm{NaI}$ detector, batteries, signal-conditioning electronics, a logic circuit, a rate meter, and an audible-alarm unit. The detector is an unshielded $3.8-$ by $1.9-\mathrm{cm} \mathrm{NaI}$ scintillator attached to a $3.8-\mathrm{cm}$-diam photomultiplier. The photomultiplier output pulses are amplified, and a lower level discriminator (LLD) is used to eliminate pulses corresponding to gamma-ray energies below $60 \mathrm{keV}$.

The LLD output is used by the logic circuitry to determine trip level and signal counts. The trip level is determined on command and is accumulated over a period that is slightly longer than 10 times the signal count interval. The trip level used is a multiple of the background count, for

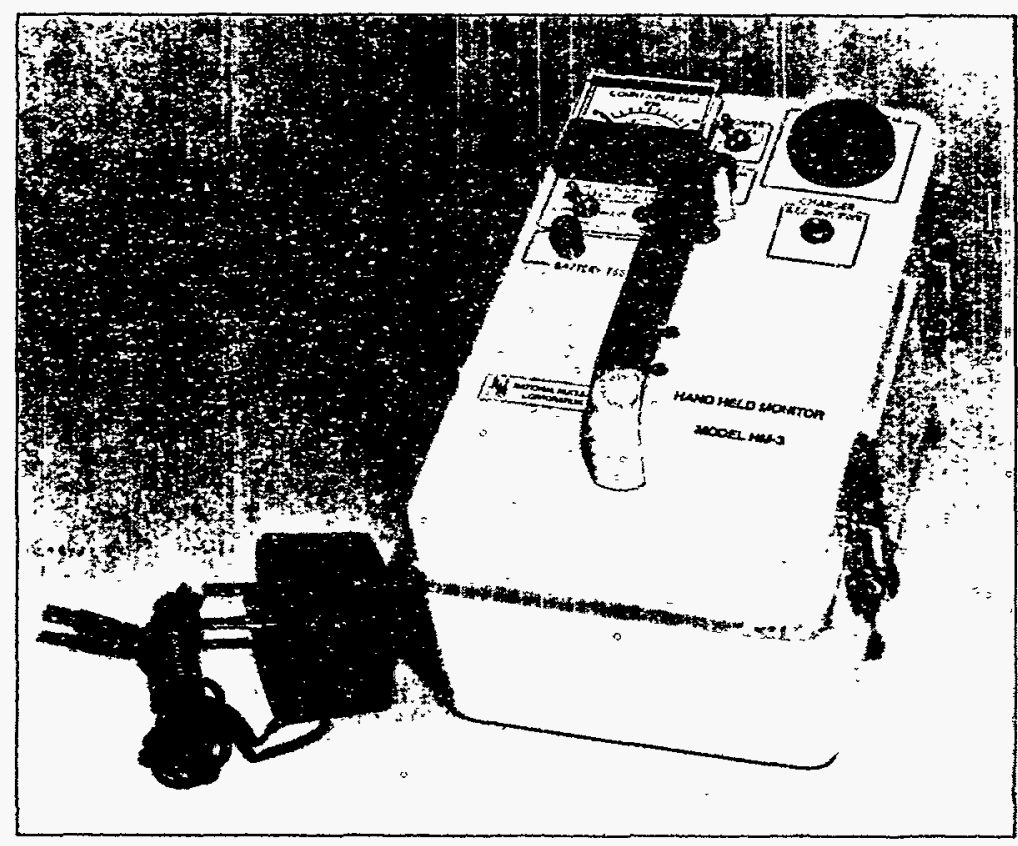

Fig. 8.

National Nuclear Corporation HM-3 hand-held monitor. 
instance, 1.3 times the mean background for a period equal to the normal count interval times the background multiplier. Here, if the count interval were $0.3 \mathrm{~s}$, a count lasting $10 \times 0.3 \times 1.3$ or $3.9^{\circ} \mathrm{s}$ would be accumulated. That count is then divided by 10 to arrive at the trip level. The signal count interval and the trip level multiplier are internally variable in units of 0.1 . Typical settings are a $0.3-\mathrm{s}$ signal count and 1.3 times background for the trip level. When the trip level is determined, the unit operates continuously in a signal mode. The accumulated signal counts above $60 \mathrm{keV}$ are compared continuously to the trip level, and if the trip level is exceeded, the audible alarm is turned on for the rest of the count interval. Thus, as signal strength increases, the audible alarms not only become more frequent but also longer. An automatic trip level update mode is also included and can be selected by connecting internal jumper wires. Automatic update may not be recommended in normal circumstances but perhaps would help when large background variations occur in the area used for vehicle searches.

The count-rate display is enabled by pressing a button, which causes the rate meter output to be indicated on the meter. Two ranges are provided and are switch selectable. Count rates that exceed the meter range are indicated by an overflow lamp. Low-voltage power is provided by an internal, rechargeable, low-voltage battery. A separate battery charger is provided. All components are mounted or padded well enough to stand a reasonable amount of shock in use.

2. Installation Requirements and Procedures. Based on experience at LASL, we believe the instrument should be operable as received from the manufacturer. There are internal adjustments that may have to be made and that require jumper changes or screwdriver potentiometer adjustments. The jumpers are solder connections and are used to vary the count interval in units of 0.1 between 0.1 and $0.9 \mathrm{~s}$ and units of 1 between 1 and $9 \mathrm{~s}$. Another jumper varies the trip level between 1.0 and 1.9 times background in steps of 0.1 . Screwdriver adjustments are used to vary the amplifier gain and LLD voltage level, which together control the gamma-ray energy window of the instrument. Should a readjustment be necessary, the procedure is to open the instrument case and remove the cushioning from the printed circuit board. Then the amplifier gain is adjusted by observing the amplifier output with an oscilloscope when $a^{60} \mathrm{Co}$ source is placed near the scintillator. The gain is increased until the amplifier saturates at the $1332-\mathrm{keV}$ peak. The LLD adjustment is made with a ${ }^{241} \mathrm{Am}$ source. The LLD is set to trigger at the $60-\mathrm{keV}$ peak. This procedure is designed to maximize ${ }^{288} \mathrm{Pu}$ sensitivity by including as much of the ingrown ${ }^{241} \mathrm{Am} 60$ $\mathrm{keV}$ radiation as possible.

Operation of the monitor requires some operator training. At LASL the training course included background information on the nature of gamma radiation. For example, the inverse square law was demonstrated and the effect of shielding materials was discussed. The instructions for use in scanning individuals direct that the operator reset the trip level before each search and that the search should consist of four vertical scans. The scans are to be equally spaced around the person, and each should be done with the instrument about $15 \mathrm{~cm}$ away from the body. Time for a single scan should be about $2 \mathrm{~s}$, and thus the total search would take about $15 \mathrm{~s}$.

To conduct vehicle searches, trainees were instructed to reset the trip level, then open all vehicle access points and scan with the instrument as close as possible to the contents, while simultaneously looking for shielding material. The response to an alarm was to initiate closer and shorter sweeps over the suspected area. The presence of a gamma-ray source would result in more frequent and longer duration sound pulses from the instrument as the source is approached.

3. Test Results. There are no test results comparable to the DOE doorway monitor evaluation. It would be best to have several individuals use the hand-held monitor to search another group of people, who may or may not have a source on them, thereby directly demonstrating the 
sensitivity of the instrument. Such tests have not been carried out, but comparative testing has been done and was used to obtain data for comparison of the use of the HSS 1050 and a conventional $\mathrm{NaI}$ gamma-ray survey meter in a search. The procedure used was to repeatedly swing a test source past the detector at a distance of $0.25 \mathrm{~m}$ and a linear speed of $0.5 \mathrm{~m} / \mathrm{s}$, which we think are typical manual scan parameters. The source used for the test was a doorway monitor test source, $10 \mathrm{~g}$ sphere of ${ }^{28} \mathrm{U}$. The background was about $25 \mu \mathrm{R} / \mathrm{h}$. Results of these tests showed almost $100 \%$ detection by the HSS 1050 compared to less than $50 \%$ by the survey meter. In use of the HHS 1050 to search people for hidden sources, the individual's body may shield the source and may reduce the background count rate. But in on-site use, the scan would be somewhat closer to the body than in the tests. We believe that the instrument should be as sensitive as a doorway monitor if it is used properly.

4. Comments. As a substitute for a doorway monitor, this instrument relies heavily on proper use by the operator. Its logic capabilities are considerably less than those in doorway monitors, and so the operator must recognize high-background situations by checking the count rate. $\mathrm{He}$ must also recognize low count rates that may indicate instrument problems. He must properly carry out search procedures, which include having the proper trip level stored. When the instrument is operated properly and sufficient time is allowed for searching, results from the hand-held monitor compare well with those from the doorway monitors.

The instrument has sufficient battery capacity to operate for about $100 \mathrm{~h}$ before recharge. A battery check test is provided.

In summary, the hand-held instrument can provide the same level of protection as a doorway monitor in low-traffic areas at about $10 \%$ of the cost. The logic unit removes much of the judgment required in using an ordinary survey meter and greatly reduces the operator training required. But, to obtain the full sensitivity of the instrument, the operator must have some training and must follow the operating instructions.

\section{BASIC INSPECTION TECHNIQUES FOR SNM DOORWAY MONITORS}

\section{A. Introduction}

As with any electronic equipment, improper use of an SNM doorway monitor can result in ineffective performance. A monitor that meets specific requirements in the laboratory or at the factory may fail to achieve the same results at a field installation for reasons that may include use at an inappropriate location, modification of the monitor during installation, improper calibration of the monitor, or outright malfunction. A way to ensure that a desired level of performance is achieved in field installation is to test the instrument at the field location under normal field operational environment. Maximum participation in the test by normal operational personnel will demonstrate their proficiency and understanding of monitor use, which indicates the effectiveness of the search procedures.

Although the intent of an inspection is to check the performance of equipment, which must meet the specifications of the revised Regulatory Guide 5.27, it cannot be done with the same precision that can be achieved in a laboratory. There are limitations to what can be done in a 1day test. In principle, we can improve the precision of the test by accumulating results over several visits. However, the on-site test is never a substitute for the laboratory evaluation, which provides the data base for field tests.

*Here, calibration means all setup procedures for the monitor electronics. 
The goal of this section is to sketch basic requirements for on-site inspection. Although the ultimate objective is a program appropriate for periodic quick inspections by a few NRC inspectors, other inspection techniques may be required during the setup of the inspection program. For example, if performance deficiencies are frequently found, it may be necessary to upgrade the equipment or to determine how to handle operational problems such as the inappropriate location of the monitor. The remedial procedure should be directed by technically trained personnel whereas the routine inspections are expected to be conducted by individuals whose background and training are in security.

The inspection procedure, whether the inspection is routine or not, needs to include a number of separate parts. The first, background radiation intensity, is particularly important because we can use the radiation background and the data base to estimate whether adequate performance should be expected. The second part, performance evaluation, involves making a series of tests to determine the detection probability per passage, which can be compared to the performance standard. In general, this part may include checking the calibration of the monitor. The final part is determining the false-alarm rate.

\section{B. Environmental Monitoring}

The two aspects of the radiation environment that concern us are the background gamma-ray intensity and how it varies in time and space.

Commercially available instruments to measure background radiation intensity range from simple hand-held survey instruments to large-volume ion-chamber instruments that are not easily portable. The differences between these two types of instruments are that the smaller instrument uses a high-efficiency $\mathrm{NaI}$ scintillator with a calibrated count rate, whereas the larger instrument uses a low-efficiency ion chamber. The large instrument can integrate the background intensity for long periods and obtain precise results. Hand-held instruments are adequate here if the display time constant is about $10 \mathrm{~s}$.

Temporal variation in background may be observed in principle by manually recording the indications of any instrument. It is perhaps most appropriate to record a logic output signal from the SNM monitor SCA by using a rate meter with a strip chart recorder. The strip chart record then indicates the monitor count-rate variation with time.

Spatial variation measurements are useful in problem situations. If an unexplained outside interference occurs with doorway monitor operation, it may be helpful to determine the origin of the radiation. This can be done with the monitor by turning it, which is not often practical, or by shielding selectively the doorway detectors. Additional instruments that might be useful for directional measurements are collimated hand-held units. The small units may lack the sensitivity to detect the variation easily, but by being portable, they can be moved around at a distance from the doorway to make additional measurements. Moving about also allows use of minimally shielded detectors for the check.

\section{Performance Evaluation}

The basic approach to performance evaluation is outlined in Appendix $\mathrm{C}$ of the revised Regulatory Guide 5.27. The idea is to simulate normal passages through the monitor with a test source positioned on the body of a person such that the source passes through the monitor where the sensitivity is relatively low. Each passage has two possible outcomes-detection or no detection-and the results of a series of passages are described by a binomial distribution. The ratio 
of detections of passages can be related to the intrinsic detection probability through the function in Fig. 1 of revised Regulatory Guide 5.27 . The figure is drawn for $50 \%$ detection probability where we want to have $95 \%$ confidence in the evaluation results. Plotting the result on Fig. 1 shows whether it falls into the crosshatched region as required.

One problem encountered in performance testing is how to make an unbiased test or, if required, a biased test that is uniformly biased. Another problem is that for a monitor with an intrinsic detection probability near $50 \%$, the result of a series of tests will not lie in the crosshatched region of Fig. 1 of revised Regulatory Guide 5.27, and thus many passages will be required. In laboratory tests, there is time for hundreds of passages, but in a field test, time is limited. The solution is to change the test criterion to the one given in Sec. V.B.

\section{False-Alarm Rate Monitoring}

The false-alarm rate is important because the statistical false-alarm rate is determined by the alarm level. In trying to meet a sensitivity requirement, the alarm level could be reduced to achieve the goal; however, a concurrent increase in false-alarm rate ensues. The drawback to high false-alarm rates is that they are a nuisance. Frequently the method chosen to reduce false alarms is to increase the alarm level; however, this decreases sensitivity and must be avoided. To avoid the problem, sensitivity requirements in the Regulatory Guide 5.27 revision are to be achieved at a statistical false-alarm rate of 1 per 1000 passages.

The field circumstances are complicated by changing background during normal operation, 80 that it is really not possible to separate out a statistical false-alarm rate. However, the total falsealarm rate is what the operator must deal with, and perhaps separating out the statistical part is only important when there is some reason to believe that the statistical rate alone is excessive. A basic problem arises when more false alarms occur than can be tolerated, and monitoring becomes a nuisance. An approach to monitoring would be to require the operator to log false alarms. When the log is examined, frequent alarms could indicate improper use of the monitor, electronic malfunction, or interference from background variability. An observed change in the alarm rate or a lower than expected rate, as given in Sec. III of this report, could indicate an operator who turns down the sensitivity during the interval between inspections.

Recording an alarm is not required by revised Regulatory Guide 5.27 , but could be administratively imposed. The response to an alarm is not considered in Regulatory Guide 5.27, and perhaps should have been covered in the Guide revision. In practice, the response procedure could be an administrative requirement. If an alarm occurs, it seems appropriate to have the occupant pass through the monitor a second time to determine if it alarms again. However, this way the operator might miss the person carrying a borderline amount of material. Therefore, each alarm should require a closer search, either a manual search or a hand-held radiation detector search. If no material is found, the operator should log a false alarm. One point in favor of the added search with radiation detectors is that it will readily identify those individuals with medical radioisotopes in their bodies (some people are not aware of them), whereas a manual search will not. Either method should detect diverted material, but the individual who is not aware that he carries a radioisotope requires unnecessary attention in a manual search each time he passes.

\section{E. Remedial Inspection}

Remedial procedures for existing equipment would determine what is needed to update the instrument components or parameters of the monitor to those used in the DOE doorway monitor 
evaluations. The changes could include narrowing the doorway; replacing or modifying amplifiers, logic units, and photomultiplier tubes; and programming changes in the microprocessor-based units. All of these changes can be done by the manufacturer. If the inspector on the initial inspection notices the deficiency, the licensee could contact the manufacturer to upgrade the monitor to the proper configuration. The work can then be done by the manufacturer's representative on a service call or done by local people with components swapped by mail.

Problems with performance require further analysis when the equipment is up to par and when the background intensity is found to be higher than the limits established in the data base. Such problems might require a remedial visit from the instrument manufacturer. However, we assume that NRC will handle such problems. The most likely method would be to look again at the monitor components to assure that they meet the requirements set in the DOE evaluations, to check the signal outputs to assure normal operation, and to calibrate the monitor by determining the optimum $\mathrm{S}^{2} / \mathrm{B}$. Background intensity and variation with time and direction may be measured precisely, and additional shielding could be recommended. If the required shielding is excessive, a new location may be needed.

Now, let us discuss the optimum $\mathrm{S}^{2} / \mathrm{B}$ window, because the concept is mentioned in several places in this report. To optimize the SCA window, we can use the fact that the monitor alarm level is a multiple of $\sqrt{\mathrm{B}}$ or, in more general terms given by Evans, ${ }^{3}$ that we are searching for a signal among statistical fluctuations that vary as $\sqrt{B}$. We measure a signal as net source counts $S$ from a particular source in the monitor and a background $\mathrm{B}$ with no source in the monitor for a series of different SCA windows. That window for which the ratio of $S$ to $\sqrt{\mathrm{B}}$ is greatest is the optimum. In practice, $S^{2} / B$ is used. Results of measurements with the three windows that have been used on the TSA monitor are shown in Table X. The optimum window clearly gives the maximum sensitivity.

TABLE X

MEASUREMENTS OF S'B MADE WITH THREE SCA WINDOWS ${ }^{a}$

\begin{tabular}{|c|c|c|c|}
\hline $\begin{array}{l}\text { SCA Window } \\
\text { (V) }\end{array}$ & $\begin{array}{c}\text { Energy Window } \\
(\mathrm{keV})\end{array}$ & $\begin{array}{c}\mathbf{S}^{2} / \mathbf{B} \\
\text { (counts/s) }\end{array}$ & $\begin{array}{l}{ }^{235} \mathrm{U} \text { Mass Needed } \\
\text { in a Spherical } \\
\text { Source to Give } \\
\text { the Same Detection } \\
\text { Probability as the } \\
\text { Optimum Window } \\
\text { (g) }\end{array}$ \\
\hline $\begin{array}{r}\text { Optimum } \\
0.3-0.85\end{array}$ & $70-215$ & 62 & 10 \\
\hline $\begin{array}{c}\text { Rocky Flats } \\
\text { Plant } \\
0.21-1.5\end{array}$ & $46-385$ & 48 & 12.2 \\
\hline $\begin{array}{l}\text { TSA } \\
0.3-7\end{array}$ & $70-1735$ & 36 & 15.2 \\
\hline
\end{tabular}




\section{DRAFT SNM DOORWAY MONITOR INSPECTION PROCEDURE}

This procedure assumes that the doorway monitor user has already carried out all of the usual calibration steps and that the monitor is operating normally.

\section{A. Background Measurement}

The background measurement should be made during the first visits and when there may be variation. It should be made when no extraneous radioactive sources are nearby. A NaI scintillator survey meter should be used, and the count-rate variation during $\sim 1$ min should be observed to establish a mean value. First, the instrument must be calibrated. For the Technical Associates PUG-1 meter, which we used, a clip-on microroentgen per hour card or Table XI can be used to determine the background in microroentgen per hour from the count rate. The table also gives estimates of the desired doorway count rate for the observed background and an optimum energy window setting.

The background measurement can be used with Table XII to determine whether adequate performance can be expected. The table covers several standard monitor configurations and, in use, the inspector should allow about $20 \%$ error. That is, we have reason to doubt that adequate performance would be achieved when the background measurement exceeds Table XII values by $20 \%$. If other than the optimum energy window is used, the display column values are still acceptable limits although the microroentgen per hour values are not.

\section{B. Performance Testing}

Regulatory Guide 5.27 (revised) gives some guidance on performance testing. We assume that the monitor is one listed in Table XII and therefore the minimum sensitivity point for testing is the center foot region of the doorway. The test source, a $10-\mathrm{g}{ }^{285} \mathrm{U}$ sphere, is to be inserted inside

TABLE XI

\section{INSTRUMENT COUNT RATE VERSUS BACKGROUND}

\begin{tabular}{|c|c|c|c|c|}
\hline \multirow[b]{2}{*}{$\begin{array}{l}\text { Background } \\
(\mu R / h)\end{array}$} & \multirow{2}{*}{$\begin{array}{c}\text { PUG-1 } \\
\text { Count Rate } \\
\text { (counts/min) } \\
\end{array}$} & \multicolumn{3}{|c|}{ Estimated Doorway Monitor Display } \\
\hline & & $\begin{array}{c}\text { NNC DM-2 } \\
\text { (counts/s) }\end{array}$ & $\begin{array}{l}\text { IRT PRM-110 } \\
\text { (counts } / 0.25 \mathrm{~s})\end{array}$ & $\begin{array}{c}\text { TSA PM-203 } \\
\text { (counts/s) }\end{array}$ \\
\hline 5 & 625 & 1100 & 400 & 92 \\
\hline 10 & 1250 & 2200 & 800 & 183 \\
\hline 15 & 1875 & 3300 & 1200 & 275 \\
\hline 20 & 2500 & 4400 & 1600 & 367 \\
\hline 25 & 3125 & 5500 & 2000 & 458 \\
\hline 30 & 3750 & 6600 & 2400 & 550 \\
\hline 35 & 4375 & 7700 & 2800 & 642 \\
\hline 40 & 5000 & 8800 & 3200 & 733 \\
\hline 45 & 5625 & 9900 & 3600 & 825 \\
\hline
\end{tabular}


TABLE XII

\section{ESTIMATED MAXIMUM BACKGROUND FOR COMMERCIAL MONITORS}

\begin{tabular}{|c|c|c|c|c|}
\hline Doorway & $\begin{array}{l}\text { Width } \\
\text { (m) }\end{array}$ & $\begin{array}{c}\text { Parameter } \\
\text { Settings }\end{array}$ & $\begin{array}{c}\text { Estimated } \\
\text { Maximum } \\
\text { Background } \\
(\mu \mathrm{R} / \mathrm{h})\end{array}$ & $\begin{array}{c}\text { Count } \\
\text { Displayed } \\
\text { (counts/s) }\end{array}$ \\
\hline \multirow[t]{2}{*}{$\begin{array}{l}\text { IRT Corp. } \\
\text { PRM-110 }\end{array}$} & $\begin{array}{l}0.76 \\
\text { (30 in.) }\end{array}$ & $\begin{array}{l}M / 2=3 \\
(M=6)\end{array}$ & 33 & $2640 / 0.25$ \\
\hline & $\begin{array}{l}0.63 \\
\text { ( } 24 \text { in.) }\end{array}$ & $\begin{array}{l}\mathrm{M} / 2=3.5 \\
(\mathrm{M}=7)\end{array}$ & 52 & $4160 / 0.25$ \\
\hline $\begin{array}{l}\text { NNC } \\
\text { DM-2 }\end{array}$ & $\begin{array}{l}0.76 \\
\text { (30 in.) }\end{array}$ & $\begin{array}{l}\text { Statistical } \\
\text { False-Alarm Rate } \\
(0.8 \text { alarms } / \mathrm{h})\end{array}$ & 33 & 7260 \\
\hline \multirow[t]{3}{*}{$\begin{array}{l}\text { TSA } \\
\text { PM-203 }\end{array}$} & $\begin{array}{l}0.61 \\
\text { (24 in.) }\end{array}$ & $\mathrm{N}$ SIGMA $=4$ & 33 & 605 \\
\hline & $\begin{array}{l}0.76 \\
(30 \text { in.) }\end{array}$ & $\mathrm{N}$ SIGMA $=4$ & 21 & 385 \\
\hline & $\begin{array}{l}0.89 \\
\text { (35 in.) }\end{array}$ & $\mathrm{N}$ SIGMA $=4$ & 15 & 275 \\
\hline
\end{tabular}

the shoe near the inside of the ankle. When testing in the foot region, care must be taken to plant the source foot so that the toe is on a line across the doorway entrance. The source foot should then swing through the doorway from a stationary start.

Walk-through performance tests should be made with no extraneous radiation sources present and with administrative control to prevent conflict between test subjects and normal traffic. Walk-throughs should be performed in small groups with about a minute delay between groups to allow the background to update. The total number of passes should be 15, made in 5 groups of 3 . The number of detections should be counted. It is important to achieve normal motion through the monitor. That is, the subject should move in the manner of the normal traffic, including stopping to present a badge. Motion should be in a single direction when only exiting traffic is monitored. If incoming traffic is also monitored, the subject should move back and forth through the monitor, being sure to turn around at a reasonable distance away from the monitor.

The results of walk-through testing are interpreted with the help of Table XIII. The first line is used for the first visit and the following lines are used for the summed results of several inspections during a year. Starting with the best results first, the performance categories are as follows.

Category 1. The number of detections for 15 trials falls in the $95 \%$ column. The required performance has been verified, and the next inspection can be scheduled in a year.

Category 2. The number of detections falls in the $70 \%$ column. The monitor must be rechecked quarterly and a running sum of the results must be maintained. By the fourth visit, the running sum of detections for 60 walk-throughs must fall in the $95 \%$ column or the monitor will fall into Category 4. 
TABLE XIII

\section{MINIMUM NUMBER OF DETECTIONS REQUIRED FOR THE INDICATED CONFIDENCE OF 50\% DETECTION PROBABILITY}

\begin{tabular}{|c|c|c|c|}
\hline \multirow[b]{2}{*}{$\begin{array}{c}\text { Number of } \\
\text { Walk-Throughs }\end{array}$} & \multicolumn{3}{|c|}{ Minimum Number of Detections } \\
\hline & $\begin{array}{c}50 \% \\
\text { Confidence }\end{array}$ & $\begin{array}{c}\mathbf{7 0 \%} \\
\text { Confidence }\end{array}$ & $\begin{array}{c}95 \% \\
\text { Confidence }\end{array}$ \\
\hline 15 & 8 & 9 & 12 \\
\hline 30 & 16 & 18 & 21 \\
\hline 45 & 24 & 26 & 30 \\
\hline 60 & 32 & 34 & 38 \\
\hline
\end{tabular}

Category 3. The number of detections falls in the $50 \%$ column. The response is the same as in Category 2 with the additional requirement that the licensee shall be directed to improve the performance before the next inspection. Some steps that can be taken are listed under Category 4.

Category 4. The number of detections falls below the $50 \%$ column. The performance is unacceptable and must be improved and the monitor must be reinspected. The inspector or user may be able to do a few things to spot possible problem areas. One preliminary check is to compare the background measurement with the maximum values listed in Table XII. If these maximums are greatly exceeded and the monitor does not have additional shielding, then excessive background is probably the basis of the poor performance. However, if the background is not excessive or added shielding is used, the monitor count display should be compared to the background measurements in Table XI. When added shielding is present, the inspector can see if the count rate has been reduced to values corresponding to those below the limit background for the standard monitors. Also, the inspector can check to see if the count display greatly exceeds what he would expect from the background measurement, which would indicate an improper monitor calibration or a malfunction.

Another preliminary check that can be made is to compare the monitor components to those listed in Table I, IV, or VII. The indicated switch settings are important. Sometimes components that differ from those listed may indicate an early model that performed poorly.

If, after a preliminary check, there do not appear to be any needed repairs or modifications that can be carried out by the licensee, it will be necessary to schedule a remedial visit by technically trained personnel.

\section{False-Alarm Rate}

The monitor log should be examined for false alarms. More than an average of $2 /$ day or $2 / 1000$ passages in high-traffic areas is deemed excessive. When the rate appears excessive, all switch settings should be checked against the settings listed in Table I, IV, or VII. For NNC monitors, no guideline is available for potentiometer settings except that if sensitivity performance will not suffer, the sensitivity dial setting can be reduced to lower the false-alarm rate. Settings should be recorded for future reference. If false alarms are still excessive, a remedial visit by a technical crew may be necessary. 


\section{Check List}

Figure 9 shows the check list that should be used to record the outcome of the inspection.

\section{TRIAL DOORWAY MONITOR INSPECTION}

\section{A. Introduction}

The end product of the LASL SNM monitor work for NRC is the documentation and trial of a procedure for performance verification of SNM doorway monitors that are installed and in use at NRC-licensed facilities. This section discusses two trials of the inspection procedure (Sec. V), along with what was learned from the trials and how we now feel NRC should proceed.

The inspections were done on separate occasions and on two commercial SNM doorway monitors. Each inspection was conducted after a manufacturer's service representative had calibrated* the doorway. The people conducting the first inspection included some of the authors of this report and two individuals who would later be responsible for the maintenance and testing of SNM monitors. The second inspection was done by the maintenance people alone.

The documents used for the trials were a preliminary draft of the inspection procedure given in Sec. V and the draft of revised Regulatory Guide 5.27 "Special Nuclear Material Doorway Monitors" (Sec. II).

\section{B. Results}

The first inspection was performed on a commercial doorway** and the results are presented in check list form in Fig. 10. The count-rate display number is much higher than would be expected from the background measured. This is because the energy window set by the manufacturer's representative was not an optimized window. The lower energy sill was determined from a short series of source measurements, but the upper sill was simply the wide-open position. Thus, the count rate was higher than it needed to be and sensitivity somewhat less than what could have been obtained. However, the performance was adequate and therefore the settings were not changed.

The manufacturer's representative felt that we were justified in testing in the foot region, particularly because the monitor was mounted on footpads to compensate for a sloping floor. A falsealarm log was not available for this monitor, so a rate evaluation was not included in the trial.

The performance obtained for the monitor was Category 1 (the best), and because the conduct of the evaluation was uncomplicated, the whole inspection was finished in less than an hour.

The recorded inspection results are presented in Fig. 11 for the second commercial monitor. Here the same discrepancy between measured background and count rate is apparent. Again, the reason is the use of an extremely wide energy window. However, the window was not reset because the "inspectors" did not have enough experience to realize the importance of this setting and because the manufacturer's representative was unfamiliar with optimization and was simply using arbitrary levels with which he was familiar. The calibration procedure outlined in the instrument manual was not used because the necessary particulars for the procedure were not recorded in the manual.

*Here, calibration means to make the necessary amplifier gain, SCA energy window, and detection logic adjustments. **We have not identified the monitor because our intent was to test our test procedure rather than carry out a thorough test of the instrument. 
NRC Doorway Monitor Inspection Check List

Date

Doorway monitor type

Location

Background measurement with PUG-1

counts/min or

$\mu \mathrm{R} / \mathrm{h}$

Doorway monitor setup parameters as available:

High voltage

Amplifier gain

Lower level discriminator

Count rate displayed

Logic unit parameters as available:

Alarm level in sigmas or sensitivity

Time constants

High-background alarm setting

Low-background alarm setting

Performance test with source located in shoe:

Detections/passes

13

13

13

13

$/ 3$

$-\frac{1}{15}$

Performance Category

False-alarm rate from log alarms/ .

Fig. 9.

Check list for on-site performance testing. 


\section{NRC Doorway Monitor Inspection Check List}

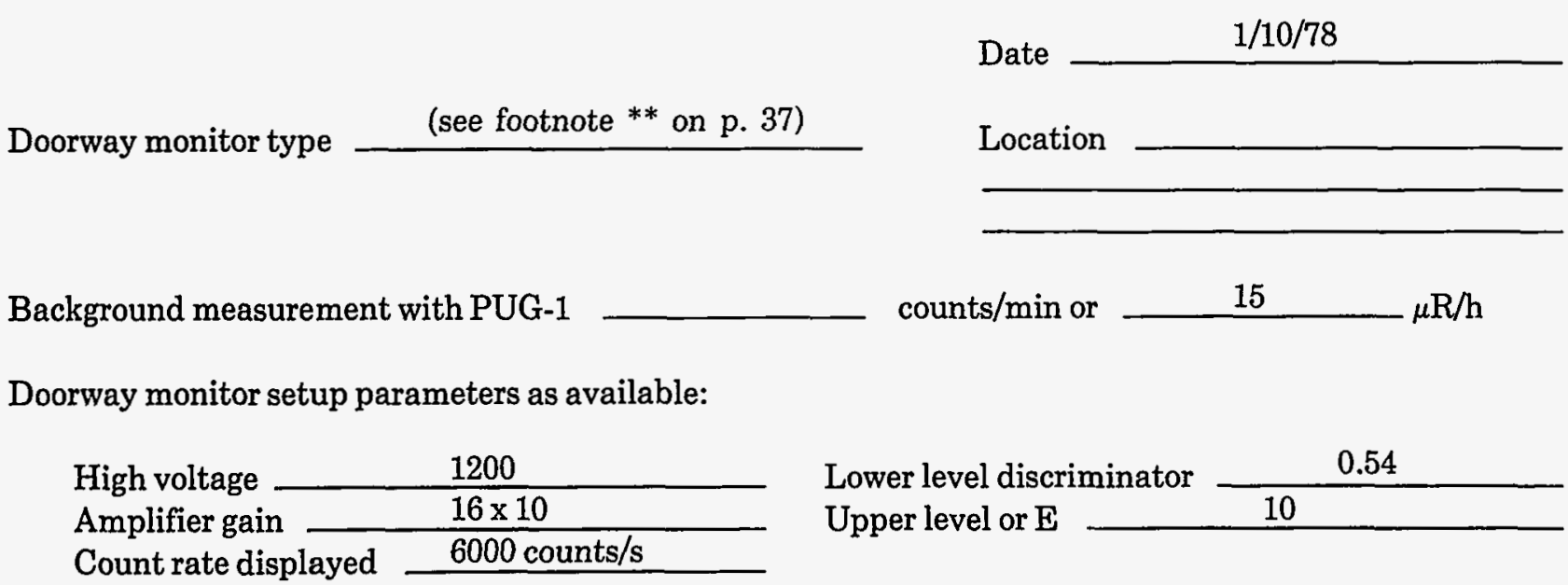

Logic unit parameters as available:

\begin{tabular}{lll} 
Alarm level in sigmas or sensitivity & 0.4 & \multicolumn{1}{c}{3.5 potentiometer setting } \\
Time constants & $\frac{20 \mathrm{~s}}{2}$ \\
\cline { 2 - 2 } High-background alarm setting & $\frac{8}{1.76}$ \\
Low-background alarm setting
\end{tabular}

Note: RATE METER $10 \%$ and $1 \times 10^{4}$

Performance test with source located in shoe:

Detections/passes

\begin{tabular}{c}
$3 / 3$ \\
$3 / 3$ \\
$3 / 3$ \\
$3 / 3$ \\
$2 / 3$ \\
\hline $14 / 15$
\end{tabular}

False-alarm rate from $\log$

Performance Category

1

not available alarms/ .

Fig. 10.

Performance test results for the first trial. 


\section{NRC Doorway Monitor Inspection Check List}

Date $1 / 20 / 78$

Doorway monitor type $\quad$ (see footnote ${ }^{* *}$ on p. 37) $\quad$ Location

Background measurement with PUG-1

1500

counts/min or

12 $\mu \mathrm{R} / \mathrm{h}$

Doorway monitor setup parameters as available:

High voltage

Amplifier gain

Count rate displayed
1700

NA

2015
Lower level discriminator

Upper level or $\mathrm{E}$
$0.6 \mathrm{~V}$

$8 \mathrm{~V}$

Logic unit parameters as available:

Alarm level in sigmas or sensitivity $M=3$

Time constants --.

High-background alarm setting

Low-background alarm setting 2000 1000

Performance test with source located in shoe:

Detections/passes

$2 / 3$

$3 / 3$

$1 / 3$

$2 / 3$

$3 / 3$

$11 / 15$

Performance Category

2

False-alarm rate from log not available alarms/ .

Fig. 11.

Performance test results for the second trial. 
A second discrepancy was that the test was carried out with the sensitivity setting of $M=3$. This was inappropriate because the monitor could not meet the DOE false-alarm performance requirement below $M=6$ in its laboratory evaluation. The $M=3$ setting was also used by the same service representative in his initial installation of the monitor; so this would appear to be an attempt to achieve good detection performance at the expense of increased false-alarm rate. Here again inexperience of the "inspectors" allowed the condition to persist.

Foot-region testing was imperative when we discovered that this monitor had included a pedestal that raised the active scintillator well above the floor, thus further reducing foot-region sensitivity.

The results of the inspection placed the monitor in Category 2. An optimum window setting would have improved the sensitivity; whereas a sensitivity setting of $M=6$ would have reduced it.

This inspection required 2 days because some equipment maintenance and training of service personnel were conducted at the same time.

\section{Digcussion}

These trials emphasized the need for training inspectors so that they are familiar with the equipment under inspection and can readily understand the possible consequences of changes that may be made in the calibration parameters. Training needed to perform the actual walkthrough testing seemed minor compared to that needed for a thorough understanding of the monitor operation principles.

The importance of optimizing the monitor calibration to achieve maximum sensitivity was not appreciated by either manufacturer's representative. NRC should provide a manual for service personnel at facilities with monitors and for inspectors that includes the basic principles of operation of the commercial monitors and procedures for achieving optimum performance. The performance procedures may properly belong in an appendix to the revised Regulatory Guide 5.27.

\section{CONTINUING SUPPORT AND DISCUSSION}

During the investigation, it became apparent that there is a need for continuing techincal support of NRC inspection activities. Some support areas are also of interest to DOE and are being done, or would be of value if they were done.

The specific areas include providing inspectors and equipment manufacturers with suitable test samples for use in evaluating performance, training inspectors in inspection procedures and making them familiar with monitor principles and operation, evaluating new commercial equipment, and providing technical assessment of problem areas.

Since the completion of this investigation, the use of SNM monitoring equipment has increased considerably. DOE-contractor material access areas are being instrumented with doorway monitors, and the hand-held monitors are being used at protected-area vehicle exits for vehicle monitoring. In addition, there are new equipment needs that soon may be adequately satisfied. Two examples are (1) the reed to search a fence perimeter after an emergency evacuation, which may be met by a simple vehicle-mounted detector array using a hand-held monitor logic package, and (2) the need to monitor personnel who may be exiting at a run during an emergency evacuation, which may be met by a new doorway monitor using large NaI detectors.

The current widespread use of SNM monitoring equipment and the prospect of increased use will require a continuing program of evaluation and testing to insure that the equipment is used effectively and that proper guidance is available to those who must purchase and use new equipment. 


\section{REFERENCES}

1. W. H. Chambers, H. F. Atwater, P. E. Fehlau, R. D. Hastings, C. N. Henry, W. E. Kuntz, T. E. Sampson, T. H. Whittlesey, and G. M. Worth, "Portal Monitor for Diversion Safeguards," Los Alamos Scientific Laboratory report LA-5681 (December 1974).

2. T. E. Sampson and P. E. Fehlau, "Sodium Iodide and Plastic Scintillator Doorway Monitor Response to Shielded Reactor Grade Plutonium," Los Alamos Scientific Laboratory report LA-6566-MS (November 1976).

3. Robley D. Evans, The Atomic Nucleus (McGraw-Hill Book Co., New York, 1955), p. 771. 